\title{
Formation of Highly Oxygenated Organic Molecules from $\alpha$-Pinene Ozonolysis: Chemical Characteristics, Mechanism, and Kinetic Model Development
}

Ugo Molteni, ${ }^{1}$ (®) Mario Simon, ${ }^{2}$ Martin Heinritzi, ${ }^{2}$ Christopher R. Hoyle, ${ }^{1, a}$ Anne-Kathrin Bernhammer, ${ }^{3}$ Federico Bianchi, ${ }^{4}$ ( Martin Breitenlechner, ${ }^{5, \mathrm{~b}}$ Sophia Brilke, ${ }^{2, \mathrm{c}}$ António Dias, ${ }^{6}$ Jonathan Duplissy, ${ }^{4,11^{(0)}}$ Carla Frege, ${ }^{1}$ Hamish Gordon, ${ }^{7}$ Claudia Heyn, ${ }^{1}$ Tuija Jokinen, ${ }^{4}$ Andreas Kürten, ${ }^{2}$ Katrianne Lehtipalo, ${ }^{4,8}$

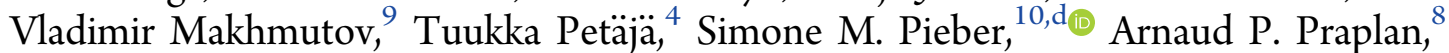
Siegfried Schobesberger, ${ }^{4,12}$ Gerhard Steiner, ${ }^{5}$ Yuri Stozhkov, ${ }^{9}$ António Tomé, ${ }^{13}$ Jasmin Tröstl, ${ }^{1}$ Andrea C. Wagner, ${ }^{2}$ Robert Wagner, ${ }^{4}$ Christina Williamson, ${ }^{2, e, f}$ Chao Yan, ${ }^{4}$ Urs Baltensperger, ${ }^{1}$ Joachim Curtius, ${ }^{2}$ Neil M. Donahue, ${ }^{14}$ Armin Hansel, ${ }^{3,5}$ Jasper Kirkby, ${ }^{2,15}$ Markku Kulmala, ${ }^{4,11,16}$ Douglas R. Worsnop, ${ }^{4,17}$ and Josef Dommen*,1

${ }^{1}$ Laboratory of Atmospheric Chemistry, Paul Scherrer Institute, CH-5232 Villigen, Switzerland

${ }^{2}$ Institute for Atmospheric and Environmental Sciences, Goethe University Frankfurt, 60438 Frankfurt am Main, Germany

${ }^{3}$ Ionicon GesmbH, 6020 Innsbruck, Austria

${ }^{4}$ Institute for Atmospheric and Earth System Research (INAR)/Physics, Faculty of Science, University of Helsinki, Post Office Box 64, FI-00014 Helsinki, Finland

${ }^{5}$ Institute for Ion and Applied Physics, University of Innsbruck, 6020 Innsbruck, Austria

${ }^{6}$ Faculty of Sciences, University of Lisbon, Campo Grande 016, 1749-016 Lisboa, Portugal

${ }^{7}$ University of Leeds, Leeds LS2 9JT, United Kingdom

${ }^{8}$ Finnish Meteorological Institute, Erik Palménin Aukio 1, 00560 Helsinki, Finland

${ }^{9}$ Lebedev Physical Institute of the Russian Academy of Sciences, Leninsky Prospekt 53, 119991 Moscow, Russia

${ }^{10}$ Department of Environmental Systems Science, ETH Zurich, 8092 Zürich, Switzerland

${ }^{11}$ Helsinki Institute of Physics, FI-00014 Helsinki, Finland

${ }^{12}$ Department of Applied Physics, University of Eastern Finland, Post Office Box 1627, 70211 Kuopio, Finland

${ }^{13}$ Instituto Dom Luiz (IDL), Universidade da Beira Interior, 6201-001 Covilhã, Portugal

${ }^{14}$ Center for Atmospheric Particle Studies, Carnegie Mellon University, Pittsburgh, Pennsylvania 15213, United States

${ }^{15} \mathrm{CERN}, \mathrm{CH}-1211$ Geneva, Switzerland

${ }^{16}$ Aerosol and Haze Laboratory, Beijing University of Chemical Technology, Beijing 100029, China

${ }^{17}$ Aerodyne Research, Incorporated, 45 Manning Road, Billerica, Massachusetts 01821, United States

Supporting Information

ABSTRACT: Terpenes are emitted by vegetation, and their oxidation in the atmosphere is an important source of secondary organic aerosol (SOA). A part of this oxidation can proceed through an autoxidation process, yielding highly oxygenated organic molecules (HOMs) with low saturation vapor pressure. They can therefore contribute, even in the absence of sulfuric acid, to new particle formation (NPF). The understanding of the autoxidation mechanism and its kinetics is still far from complete. Here, we present a mechanistic and kinetic analysis of mass spectrometry data from $\alpha$-pinene (AP) ozonolysis experiments

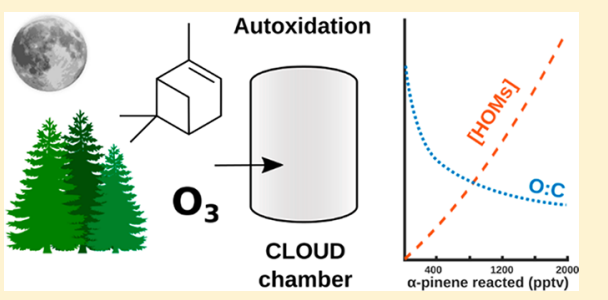
performed during the CLOUD 8 campaign at CERN. We grouped HOMs in classes according to their identified chemical composition and investigated the relative changes of these groups and their continued...

Received: February 13, 2019

Revised: April 2, 2019

Accepted: April 3, 2019

Published: April 3, 2019 
components as a function of the reagent concentration. We determined reaction rate constants for the different HOM peroxy radical reaction pathways. The accretion reaction between HOM peroxy radicals was found to be extremely fast. We developed a pseudo-mechanism for HOM formation and added it to the AP oxidation scheme of the Master Chemical Mechanism (MCM). With this extended model, the observed concentrations and trends in HOM formation were successfully simulated.

KEYWORDS: HOM, terpene oxidation, autoxidation, dimers, peroxy radicals, chamber study, CLOUD, atmospheric oxidation mechanism

\section{INTRODUCTION}

Biogenic volatile organic compounds (BVOCs) comprise the largest fraction of total volatile organic compounds (VOCs) in the atmosphere, with an estimated emission rate of $760 \mathrm{Tg}$ of $\mathrm{C}$ per year. ${ }^{1}$ Isoprene and terpenes dominate, among which $\alpha$ pinene (AP) accounts for $32 \mathrm{Tg}$ of $\mathrm{C}$ year $^{-1}$ or $34 \%$ of the total yearly terpene emissions. ${ }^{1}$ In the atmosphere, $\mathrm{AP}$ is oxidized by ozone $\left(\mathrm{O}_{3}\right)$, hydroxyl radicals $(\mathrm{OH})$, and nitrate radicals $\left(\mathrm{NO}_{3}\right){ }^{2}$ A substantial fraction of the oxidation products contributes to the formation of secondary organic aerosol (SOA). As shown recently, the oxidation of AP involves an autoxidation pathway that leads to highly oxygenated organic molecules, denoted here as HOMs. ${ }^{3-6}$ HOMs hold several oxygen-containing functional groups, in particular, hydroperoxides. As a result of their low volatility, AP HOMs can nucleate, even in the absence of sulfuric acid, at atmospherically relevant conditions ${ }^{7}$ and can support the early growth of nanoparticles. ${ }^{8,9}$ HOMs have also been identified in the ambient atmosphere and linked to new particle formation (NPF) events at various sites. ${ }^{10-12} \mathrm{NPF}$ in the absence of sulfuric acid is especially important for a full understanding of the formation of cloud condensation nuclei and the cloud properties before the Industrial Revolution, when sulfur had no anthropogenic sources, and, consequently, for the assessment of today's climate sensitivity. ${ }^{13,14} \mathrm{HOM}$ formation has been observed in the oxidation of monoterpenes, ${ }^{4,15,16}$ sesquiterpenes, ${ }^{17,18}$ isoprene, ${ }^{15}$ cycloalkenes, ${ }^{19-22}$ which are mostly from biological sources, and also aromatics, ${ }^{23-25}$ which are mainly emitted from anthropogenic sources. The different chemical structures of the precursors, the type of oxidants, and the presence of radicals, such as nitrogen oxide ( $\mathrm{NO})$, nitrogen dioxide $\left(\mathrm{NO}_{2}\right)$, and peroxyl radicals $\left(\mathrm{HO}_{2}\right.$ and $\left.\mathrm{RO}_{2}\right)$, influence the chemical composition and molar yield of HOMs. ${ }^{4,21,26}$ The autoxidation mechanism is thought to start with a peroxy radical and proceeds via an internal hydrogen abstraction of a weakly bound hydrogen atom, forming a hydroperoxyalkyl radical, which, in turn, rapidly reacts with oxygen to a new peroxy radical. ${ }^{6}$ Recent findings also suggest that, in some cases, the radical propagation chain can be sustained by the formation of an endoperoxy ring in the presence of a still intact double bond. ${ }^{27}$ Both of these types of radical propagation chains can lead to the very high oxygen content and oxygen/carbon ratio $(\mathrm{O} / \mathrm{C})$ found in HOMs.

We performed a series of AP ozonolysis experiments at various atmospherically relevant concentrations to study NPF. Kirkby et al. and Tröstl et al. ${ }^{7,9}$ demonstrated that HOM monomers and HOM dimers drive the NPF and early growth. Here, we present a chemical framework of HOM formation from AP ozonolysis based on previous work on cyclohexene ${ }^{22}$ and include this in the Master Chemical Mechanism (MCM) for $\mathrm{AP}^{28,29}$ The influence of the AP concentration (i.e., a varying oxidation rate) on the total $\mathrm{HOM} \mathrm{O} / \mathrm{C}$ and the relative HOM concentrations was investigated, and reaction rate constants for some peroxy-peroxy radical reactions leading to some specific HOM classes were determined. Reaction rate constants of the autoxidation mechanism in the extended MCM were constrained to fit the measured data.

\section{EXPERIMENTAL SECTION}

We performed experiments at the CERN Cosmics Leaving Outdoor Droplets (CLOUD) chamber during the CLOUD 8 campaign (Oct-Nov 2013). They are discussed in detail by Kirkby et al. $^{7}$ and the Supporting Information. In brief, the CLOUD chamber is a $26.1 \mathrm{~m}^{3}$ electropolished stainless-steel continuously stirred tank reactor, which is operated at ultraclean standards. Experiments are conducted using synthetic air produced by evaporation of cryogenic nitrogen and oxygen, and humidification uses ultraclean water, which ensures extremely low levels of contamination with organic vapors (sub-pptv level). ${ }^{7,30}$ Experiments were performed at $278 \mathrm{~K}, 38 \%$ relative humidity $(\mathrm{RH})$, and an ozone $\left(\mathrm{O}_{3}\right)$ mixing ratio of $30-$ 35 ppbv. Background sulfuric acid was below $5 \times 10^{4}$ molecules $\mathrm{cm}^{-3}$ at dark conditions (i.e., no active photochemistry). $\mathrm{OH}$ radicals formed only as a side product of the AP ozonolysis. We injected AP at stable chamber conditions by use of an evaporation system and monitored its concentration with a proton transfer reaction time-of-flight mass spectrometer (PTR-TOF-MS). ${ }^{31}$ We conducted 10 experiments, with AP ranging from 17 to $1692 \mathrm{pptv}$ (Table S1 of the Supporting Information). We measured gas-phase HOMs from AP ozonolysis with a nitrate chemical ionization mass spectrometer (nitrate-CIMS) as either anions or nitrate clusters. ${ }^{3,32} \mathrm{We}$ analyzed CIMS data using MATLAB/TofTools. ${ }^{33}$ In the absence of a suitable HOM compound as a calibrant, we calibrated with sulfuric acid and used this calibration factor for the HOM clusters, ${ }^{4}$ correcting for measured mass-dependent ion transmission efficiency ${ }^{34}$ and also taking sampling line losses into account. ${ }^{7}$ We estimate the uncertainty to be in a range from -50 to $+100 \%$.

\section{CHEMICAL MECHANISM DESCRIPTION}

3.1. HOM Formation from Ozonolysis. We derived a pseudo-mechanism for AP ozonolysis autoxidation analogous to the scheme developed previously by Mentel et al. ${ }^{22}$ for cycloalkenes and also presented in a recent review. ${ }^{35}$ We extend this mechanism to better represent observed alkoxy radical pathways, carbon chain fragmentation, and dimer formation. The AP $\left(\mathrm{C}_{10} \mathrm{H}_{16}\right)$ ozonolysis is initiated by an ozone addition to the double bond leading to the so-called primary ozonide $\left(\mathrm{C}_{10} \mathrm{H}_{16} \mathrm{O}_{3}\right)$ as an intermediate product. The cleavage of an oxygen-oxygen bond in the primary ozonide yields four different carbonyl oxide (Criegee intermediate) isomers $\left(\mathrm{C}_{10} \mathrm{H}_{16} \mathrm{O}_{3}\right)$. Three of these Criegee intermediate isomers can isomerize via a 1,4-hydrogen shift reaction and lead to vinylhydroperoxides $\left(\mathrm{C}_{10} \mathrm{H}_{16} \mathrm{O}_{3}\right)$. These decompose via $\mathrm{O}-\mathrm{O}$ bond scission, yielding an $\mathrm{OH}$ radical and a vinoxy radical $\left(\mathrm{C}_{10} \mathrm{H}_{15} \mathrm{O}_{2}\right)$, which, in turn, takes up a molecule of oxygen from the atmosphere, yielding the initial peroxy radicals $\left(\mathrm{C}_{10} \mathrm{H}_{15} \mathrm{O}_{4}\right)$. This peroxy radical is thought to be the initiator of the so-called 
autoxidation mechanism, which yields, via consecutive molecular oxygen additions, HOMs. ${ }^{36}$ Here, we treat all constitutional isomers as a single compound. The possible reactions involved in the autoxidation mechanism are given by reactions R1-R5 and illustrated in Scheme S1 of the Supporting Information in a generalized framework.

$$
\begin{aligned}
& \mathrm{RO}_{2} \rightarrow \text { QOOH; QOOH }+\mathrm{O}_{2} \rightarrow \mathrm{R}(\mathrm{OOH}) \mathrm{O}_{2} \\
& \text { autoxidation path }\left(\mathrm{C}_{10} \mathrm{H}_{15} \mathrm{O}_{2+2 n}\right) \\
& \mathrm{RO}_{2} \rightarrow \mathrm{R}_{\mathrm{H}} \mathrm{O}+\mathrm{OH} \\
& \text { carbonyl channel }\left(\mathrm{C}_{10} \mathrm{H}_{14} \mathrm{O}_{(2+2 n-1)}\right) \\
& \mathrm{RO}_{2}+\mathrm{HO}_{2} \rightarrow \mathrm{ROOH}+\mathrm{O}_{2} \\
& \text { hydroperoxide channel }\left(\mathrm{C}_{10} \mathrm{H}_{16} \mathrm{O}_{(2+2 n)}\right) \\
& \mathrm{RO}_{2}+\mathrm{HO}_{2} \rightarrow \mathrm{RO}+\mathrm{OH}+\mathrm{O}_{2} \\
& \text { alkoxy radical channel }\left(\mathrm{C}_{10} \mathrm{H}_{15} \mathrm{O}_{(2+2 n-1)}\right) \\
& \mathrm{RO}_{2}+\mathrm{R}^{\prime} \mathrm{O}_{2} \rightarrow \mathrm{ROH}+\mathrm{R}_{\mathrm{H}}^{\prime} \mathrm{O}+\mathrm{O}_{2} \\
& \text { carbonyl }\left(\mathrm{C}_{10} \mathrm{H}_{14} \mathrm{O}_{(2+2 n-1)}\right) \text { or hydroxyl channel } \\
& \quad\left(\mathrm{C}_{10} \mathrm{H}_{16} \mathrm{O}_{(2+2 n-1)}\right) \\
& \mathrm{RO}_{2}+\mathrm{R}^{\prime} \mathrm{O}_{2} \rightarrow \mathrm{RO}+\mathrm{R}^{\prime} \mathrm{O}+\mathrm{O}_{2} \\
& \text { alkoxy radical channel }\left(\mathrm{C}_{10} \mathrm{H}_{15} \mathrm{O}_{(2+2 n-1)}\right) \\
& \mathrm{RO}_{2}+\mathrm{R}^{\prime} \mathrm{O}_{2} \rightarrow \mathrm{ROOR}+\mathrm{O}_{2} \\
& \mathrm{RO}+\mathrm{O}_{2} \rightarrow \mathrm{R}_{\mathrm{H}} \mathrm{O}+\mathrm{HO}_{2} \\
& \text { carbonyl channel }\left(\mathrm{C}_{10} \mathrm{H}_{14} \mathrm{O}_{(2+2 n-1)}\right)
\end{aligned}
$$

The initial peroxy radical $\left(\mathrm{C}_{10} \mathrm{H}_{15} \mathrm{O}_{4}\right)$ can follow the autoxidation path by rearranging via a hydrogen shift to a carbon-centered radical $(\mathrm{QOOH}$, long recognized in combustion chemistry ${ }^{37}$ ), which subsequently adds molecular oxygen (reaction R1). Repeating cycles of this process can lead to observed peroxy radicals with up to 12 oxygen atoms (molecular formula of $\mathrm{C}_{10} \mathrm{H}_{15} \mathrm{O}_{12}$ ), with each step increasing the oxygen content by 2 atoms. The general molecular formula of these peroxy radicals can therefore be represented as $\mathrm{C}_{10} \mathrm{H}_{15} \mathrm{O}_{2+2 n}$, where $n$ is the number of oxygen molecules that the vinoxy radical takes up during the autoxidation. Previous work has shown that the radical chain can be terminated when the hydrogen shift occurs in geminal position to a pre-existing hydroperoxy group. ${ }^{19}$ This reaction eliminates an $\mathrm{OH}$ radical and forms a closed-shell molecule with the general formula $\mathrm{C}_{10} \mathrm{H}_{14} \mathrm{O}_{(2+2 n-1)}$ terminated with a carbonyl functional group (reaction R2). Because this unimolecular termination step requires the presence of at least one hydroperoxide group in the molecule, the first suitable peroxy radical is the $\mathrm{C}_{10} \mathrm{H}_{15} \mathrm{O}_{6}$ radical. The $\mathrm{C}_{10} \mathrm{H}_{15} \mathrm{O}_{(2+2 n)}$ radical can also react with a hydroperoxy radical $\left(\mathrm{HO}_{2}\right)$, yielding either a hydroperoxide functional group (reaction R3a) with general formula $\mathrm{C}_{10} \mathrm{H}_{16} \mathrm{O}_{(2+2 n)}$ or an alkoxy radical with general formula $\mathrm{C}_{10} \mathrm{H}_{15} \mathrm{O}_{(2+2 n-1)}$ (reaction R3b). Similarly, the HOM-peroxy radicals $\left(\mathrm{RO}_{2}\right)$ can react with any other peroxy radical $\left(\mathrm{R}^{\prime} \mathrm{O}_{2}\right)$ according to reactions $\mathrm{R} 4 \mathrm{a}-\mathrm{R} 4 \mathrm{c}$. Thus, a radical with the formula $\mathrm{C}_{10} \mathrm{H}_{15} \mathrm{O}_{(2+2 n)}$ can undergo a disproportionation reaction (reaction $\mathrm{R} 4 \mathrm{a}$ ), yielding either a carbonyl functional group (carbonyl channel) with general formula $\mathrm{C}_{10} \mathrm{H}_{14} \mathrm{O}_{(2+2 \mathrm{n}-1)}$ or alternately a hydroxyl functional group (hydroxy channel) with general formula $\mathrm{C}_{10} \mathrm{H}_{16} \mathrm{O}_{(2+2 n-1)}$. Furthermore, reaction $\mathrm{R} 4 \mathrm{~b}$ leads to the formation of an alkoxy radical ( $\mathrm{RO}$ ) with general formula $\mathrm{C}_{10} \mathrm{H}_{15} \mathrm{O}_{(2+2 n-1)}$. Reaction $\mathrm{R} 4 \mathrm{c}$ is thought to generate dimers via a peroxy bond formation, as discussed further in section 3.4. ${ }^{7,25}$ With this framework, the firstgeneration HOMs can be rationalized on the basis of their molecular formula, $n_{\mathrm{C}} n_{\mathrm{H}} n_{\mathrm{O}}$, giving the number of carbon, hydrogen, and oxygen atoms.

Alkoxy radicals formed from reactions $\mathrm{R} 3 \mathrm{~b}$ and $\mathrm{R} 4 \mathrm{~b}$ can follow several pathways. Except for ternary alkoxy radicals, they can react with molecular oxygen according to reaction $\mathrm{R} 5$, producing compounds with general formula $\mathrm{C}_{10} \mathrm{H}_{14} \mathrm{O}_{(2+2 n-1)}$. Alternatively, as shown in Scheme 1, they can undergo internal

\section{Scheme 1. Alkoxy Radical Rearrangements*}<smiles>[R]CCC([R])O</smiles><smiles>[R]C1CC2([O-])CC1C2[O-]</smiles><smiles>[R]C(=O)CC([R])CCC</smiles>
R6b<smiles>[R]CC1CCOC1[R]</smiles><smiles>[R]C=CC</smiles><smiles>[CH2-]P</smiles>

R6c

*Reported possible unimolecular rearrangements for the alkoxy radical: hydrogen abstraction (reaction R6a), ring opening (reaction $\mathrm{R} 6 \mathrm{~b}$ ), and molecular fragmentation (reaction R6c). With reactions $\mathrm{R} 6 \mathrm{a}$ and $\mathrm{R} 6 \mathrm{~b}$, the $\mathrm{C}_{10}$ carbon backbone is preserved, while reaction R6c leads to two fragments of variable length.

molecular rearrangements, including hydrogen shift (reaction R6a), ring opening (reaction R6b), or fragmentation of the carbon chain (reaction R6c). The hydrogen shift reaction (reaction R6a), similar to the autoxidation mechanism, leads to a carbon-centered radical and a hydroxyl group. A ring-opening reaction (reaction $\mathrm{R} 6 \mathrm{~b}$ ) was already postulated ${ }^{36}$ as an important step to overcome steric hindrance in the autoxidation pathway to highly oxygenated organic molecules.

The ring-opening pathway proceeds via the formation of a carbonyl group and a carbon-centered radical. The carboncentered radicals, formed either by hydrogen shift or ring opening, can subsequently take up molecular oxygen and eventually continue the autoxidation mechanism, leading to a class of peroxy radicals with the general formula $\mathrm{C}_{10} \mathrm{H}_{15} \mathrm{O}_{(2+2 n-1)}$. When the alkoxy radical does not dissociate on a ring, the reaction (reaction $\mathrm{R} 6 \mathrm{c}$ ) results in the formation of two fragments. Peroxy radicals produced via an alkoxy radical step and subsequent rearrangement reactions (reactions R6a and $\mathrm{R} 6 \mathrm{~b}$ ) have the chemical formula $\mathrm{C}_{10} \mathrm{H}_{15} \mathrm{O}_{(2+2 n-1)}$. All of the observed compounds with this chemical formula are assumed to be peroxy radicals as a result of the very short lifetime of the alkoxy radicals with the same composition. We assume that they also react according to reactions R1-R4 (Scheme S2 of the 
Table 1. $\mathrm{C}_{10}$ Monomer Classification*

\begin{tabular}{|c|c|c|c|c|c|}
\hline & 14 hydrogens & 15 hydrogens & 16 hydrogens & 17 hydrogens & 18 hydrogens \\
\hline $\begin{array}{c}\text { Even } \\
\text { O }\end{array}$ & $\begin{array}{c}\text { unimolecular R2, } \\
\text { carbonyl R4a, } \\
\text { alkoxy- } \mathrm{O}_{2} \text { R5 }\end{array}$ & $\begin{array}{l}\text { primary } \\
\text { radical R1 }\end{array}$ & $\begin{array}{l}\text { hydroperoxyl R3a, } \\
\text { hydroxyl R4a, } \\
\text { unimolecular R2, } \\
\text { carbonyl R4a, } \\
\text { alkoxy-O2 R5 }\end{array}$ & alkoxy R1 & $\begin{array}{l}\text { hydroxyl } \\
\text { R4a }\end{array}$ \\
\hline $\begin{array}{c}\text { Odd } \\
\text { O }\end{array}$ & $\begin{array}{c}\text { unimolecular R2, } \\
\text { carbonyl R4a, } \\
\text { alkoxy- } \mathrm{O}_{2} \text { R5 }\end{array}$ & alkoxy R1 & $\begin{array}{c}\text { hydroxyl R4a, } \\
\text { hydroperoxyl R3a }\end{array}$ & $\begin{array}{l}\text { primary } \\
\text { radical R1 }\end{array}$ & $\begin{array}{c}\text { hydroperoxyl } \\
\text { R3a }\end{array}$ \\
\hline
\end{tabular}

* In gray, first-generation products from the AP ozonolysis without the alkoxy autoxidation pathway (Scheme S1 of the Supporting Information); in blue, products from the AP ozonolysis that went through an alkoxy rearrangement step (Scheme S2 of the Supporting Information); and in orange, first-generation products from the OH addition autoxidation mechanism (Scheme S3 of the Supporting Information). The reaction pathway to the products is also indicated.

Supporting Information). The entry point into this scheme can be by species with different oxygen atom contents depending upon the number of autoxidation cycles before the alkoxy step occurs. Along this alkoxy pathway, reaction $\mathrm{R} 2$ leads to compounds with general formula $\mathrm{C}_{10} \mathrm{H}_{14} \mathrm{O}_{(2+2 n-2)}$ (only for $n$ $>2$ ), reaction $\mathrm{R} 3 \mathrm{a}$ to $\mathrm{C}_{10} \mathrm{H}_{16} \mathrm{O}_{(2+2 n-1)}$ (only for $n>1$ ), and reaction $\mathrm{R} 4 \mathrm{a}$ to $\mathrm{C}_{10} \mathrm{H}_{14} \mathrm{O}_{(2+2 n-2)}$ and $\mathrm{C}_{10} \mathrm{H}_{16} \mathrm{O}_{(2+2 n-2)}$ (only for $n$ $>2$ ). A second-generation alkoxy radical intermediate can be formed via reactions $\mathrm{R} 3 \mathrm{~b}$ and $\mathrm{R} 4 \mathrm{~b}$, but here, we do not treat further reaction steps from there.

3.2. Monomer $\mathrm{C}_{10} \mathrm{HOMs}$ from $\mathrm{OH}$ Reactions. Ozonolysis of $\mathrm{AP}$ yields $\mathrm{OH}$ radicals (see above), which can react with $\mathrm{AP}$ by either hydrogen abstraction or $\mathrm{OH}$ radical addition. Hydrogen abstraction is considered a minor pathway and accounts for only $12 \%$ of reacted $\mathrm{AP} .{ }^{16}$ For this reason, it is not further considered here. An $\mathrm{OH}$ radical addition to the double bond results in a carbon-centered radical with formula $\mathrm{C}_{10} \mathrm{H}_{17} \mathrm{O}$ that can undergo an autoxidation mechanism ${ }^{16}$ and yield peroxy radicals with the general formula $\mathrm{C}_{10} \mathrm{H}_{17} \mathrm{O}_{(1+2 n)}$. We assume that the reaction framework described above (reactions R4-R6) can also be applied to this class of peroxy radicals. The peroxy radicals and closed-shell oxidation products from these reactions contain 16-18 hydrogens (Scheme S3 of the Supporting Information). On the basis of the different combinations of hydrogen and oxygen atoms, the products from the autoxidation mechanism can be separated into 10 different classes (Table 1). It appears that specific combinations of hydrogen number with an even or odd oxygen number can be used to constrain and study certain chemical pathways.

3.3. Fragmentation Products. Following reaction R6c (Scheme 1), alkoxy radicals can undergo $\mathrm{C}-\mathrm{C}$ bond fission of the carbon chain to produce two fragments: one with a carbonyl functional group, while the other one is a carbon-centered radical. In principle, the fragmentation may happen every time a peroxy radical is converted to an alkoxy radical. Because the fragmentation can occur at different positions of the carbon skeleton, fragments of different lengths (e.g., 9-1, 8-2, and 7-3 carbon atoms each) are formed. This is exemplified on three peroxy radical $\mathrm{C}_{10} \mathrm{H}_{15} \mathrm{O}_{4}$ structures in Scheme $\mathrm{S} 4$ of the Supporting Information. We included the radicals with carbon numbers of 8 and $9\left(\mathrm{C}_{9} \mathrm{H}_{15} \mathrm{O}_{x}, \mathrm{C}_{9} \mathrm{H}_{13} \mathrm{O}_{x}, \mathrm{C}_{8} \mathrm{H}_{13} \mathrm{O}_{x}, \mathrm{C}_{9} \mathrm{H}_{17} \mathrm{O}_{x}\right.$ and $\mathrm{C}_{8} \mathrm{H}_{15} \mathrm{O}_{x}$ ) in the mechanism (Scheme $\mathrm{S} 5$ of the Supporting Information). These carbon-centered radicals are rapidly converted to peroxy radicals by the addition of molecular oxygen and can react further by autoxidation (reactions R1 and $\mathrm{R} 2$ ) or reactions $\mathrm{R} 3$ and $\mathrm{R} 4$.

3.4. Dimer Formation. It has been proposed that peroxy radicals can associate to form a dimer molecule combining the carbon backbones of both radicals via a peroxy bond (reaction $\mathrm{R} 4 \mathrm{c}$ ). Although this mechanism was believed to be either slow or even spin-forbidden, ${ }^{38}$ others ${ }^{25}$ recently demonstrated experimentally that this reaction is very fast for HOM-like peroxy radicals. Therefore, in our reaction scheme, all combinations of reactions of $\mathrm{C}_{10} \mathrm{H}_{15} \mathrm{O}_{(2+2 n)}$ and $\mathrm{C}_{10} \mathrm{H}_{15} \mathrm{O}_{(2+2 n-1)}$ peroxy radicals were included, yielding the following dimers:

$$
\begin{gathered}
\mathrm{C}_{10} \mathrm{H}_{15} \mathrm{O}_{(2+2 n)}+\mathrm{C}_{10} \mathrm{H}_{15} \mathrm{O}_{(2+2 m)} \\
\rightarrow \mathrm{C}_{20} \mathrm{H}_{30} \mathrm{O}_{(4+2 n+2 m-2)}+\mathrm{O}_{2} \\
\mathrm{C}_{10} \mathrm{H}_{15} \mathrm{O}_{(2+2 n)}+\mathrm{C}_{10} \mathrm{H}_{15} \mathrm{O}_{(2+2 m-1)} \\
\rightarrow \mathrm{C}_{20} \mathrm{H}_{30} \mathrm{O}_{(4+2 n+2 m-1-2)}+\mathrm{O}_{2} \\
\mathrm{C}_{10} \mathrm{H}_{15} \mathrm{O}_{(2+2 n-1)}+\mathrm{C}_{10} \mathrm{H}_{15} \mathrm{O}_{(2+2 m-1)} \\
\rightarrow \mathrm{C}_{20} \mathrm{H}_{30} \mathrm{O}_{(4+2 n+2 m-2-2)}+\mathrm{O}_{2}
\end{gathered}
$$

Reactions R7a and R7c always yield dimers with an even number of oxygen atoms, while reaction $\mathrm{R} 7 \mathrm{~b}$ yields dimer molecules with an odd number of oxygen atoms. Additionally, reactions of peroxy radicals from fragmentation pathways with 8 and 9 carbon atoms generate another series of dimers: $\mathrm{C}_{\mathbf{1 6}} \mathrm{H}_{\mathbf{2 6}} \mathrm{O}_{x}$, $\mathrm{C}_{16} \mathrm{H}_{28} \mathrm{O}_{x}, \quad \mathrm{C}_{16} \mathrm{H}_{30} \mathrm{O}_{x}, \quad \mathrm{C}_{17} \mathrm{H}_{26} \mathrm{O}_{x}, \quad \mathrm{C}_{17} \mathrm{H}_{28} \mathrm{O}_{x}, \quad \mathrm{C}_{17} \mathrm{H}_{30} \mathrm{O}_{x}$, $\mathrm{C}_{17} \mathrm{H}_{32} \mathrm{O}_{x}, \mathrm{C}_{18} \mathrm{H}_{26} \mathrm{O}_{x}, \mathrm{C}_{18} \mathrm{H}_{28} \mathrm{O}_{x}, \mathrm{C}_{18} \mathrm{H}_{30} \mathrm{O}_{x}, \mathrm{C}_{18} \mathrm{H}_{32} \mathrm{O}_{x}$, $\mathrm{C}_{18} \mathrm{H}_{34} \mathrm{O}_{x}, \quad \mathrm{C}_{19} \mathrm{H}_{28} \mathrm{O}_{x}, \quad \mathrm{C}_{19} \mathrm{H}_{30} \mathrm{O}_{x}, \mathrm{C}_{19} \mathrm{H}_{32} \mathrm{O}_{x}, \mathrm{C}_{19} \mathrm{H}_{34} \mathrm{O}_{x}$, $\mathrm{C}_{20} \mathrm{H}_{30} \mathrm{O}_{x}, \mathrm{C}_{20} \mathrm{H}_{32} \mathrm{O}_{x}$, and $\mathrm{C}_{20} \mathrm{H}_{34} \mathrm{O}_{x}$. Among these, we observed, in the experimental data, the 14 classes shown in bold and failed to observe only the five classes shown in a normal font.

\section{RESULTS}

The following three sections describe how we integrated the mechanistic scheme to the measurements. In the first section, we present the measured HOM distribution and concentration trends with experimental conditions. For each experiment, we focus on data when AP and HOM (major species) concentrations reached a plateau, meaning that sources (vapors injection and chemical production) and sinks (chemical reactions, wall and particle losses, and dilution) were in a steady 

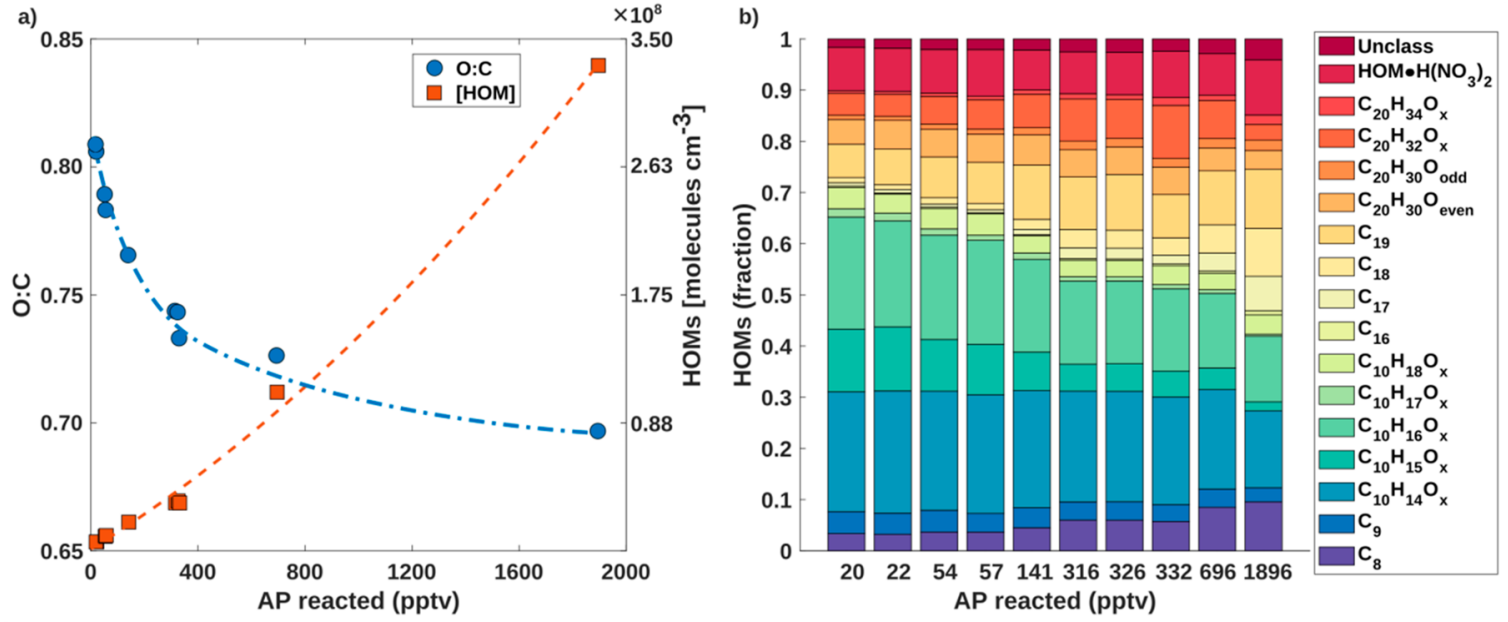

Figure 1. (a) HOM concentration and average $\mathrm{O} / \mathrm{C}$ as a function of reacted AP. The HOM concentration (in orange) is corrected for wall loss and the condensational sink on particles. In blue, the average O/C of all HOMs is displayed. The curves are to guide the eye. An increase in reacted AP leads to less oxygenated HOMs. (b) Relative contributions of $\mathrm{HOM}$ classes at different amounts of $\mathrm{AP}_{\text {react }}$. HOMs with $11-15$ carbon atoms are grouped as unclassified (Unclass).
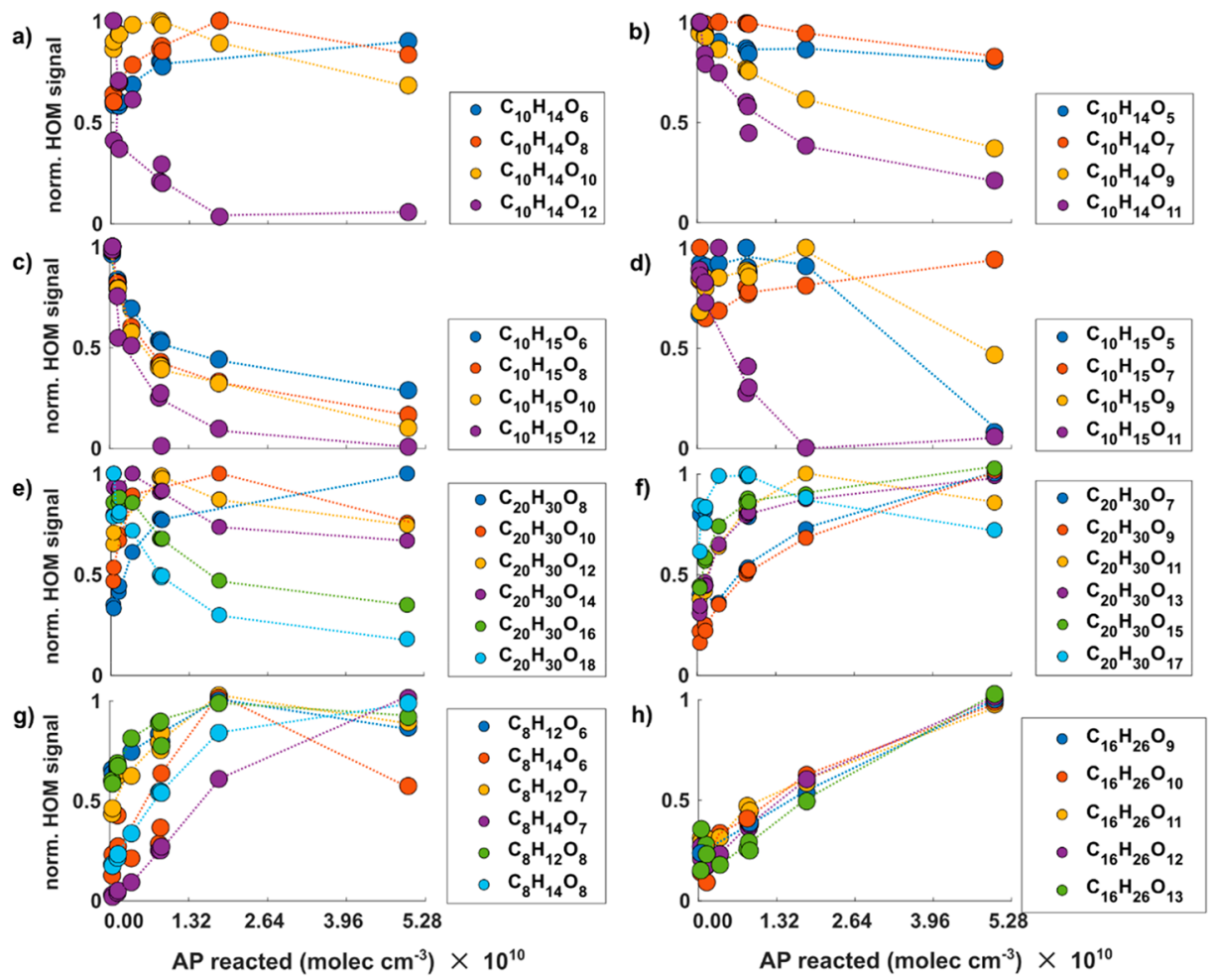

Figure 2. $(\mathrm{a}-\mathrm{d})$ Trends of relative contributions of $\mathrm{C}_{10}$ monomers in different classes as a function of $\mathrm{AP}$ reacted: $(\mathrm{a}) \mathrm{C}_{10} \mathrm{H}_{14} \mathrm{O}_{\text {even }}(\mathrm{O}=6,8,10$, and 12), (b) $\mathrm{C}_{10} \mathrm{H}_{14} \mathrm{O}_{\text {odd }}\left(\mathrm{O}=5,7,9\right.$, and 11), (c) $\mathrm{C}_{10} \mathrm{H}_{15} \mathrm{O}_{\text {even }}\left(\mathrm{O}=6,8,10\right.$, and 12), and (d) $\mathrm{C}_{10} \mathrm{H}_{15} \mathrm{O}_{\text {odd }}\left(\mathrm{O}=5\right.$, 7, 9, and 11). (e and f) $\mathrm{C}_{20}$ dimer fractions for different classes and within classes as a function of the AP reacted: $(e) \mathrm{C}_{20} \mathrm{H}_{30} \mathrm{O}_{\text {even }}(\mathrm{O}=8,10,12,14,16$, and 18$)$ and $(\mathrm{f}) \mathrm{C}_{20} \mathrm{H}_{30} \mathrm{O}_{\text {odd }}(\mathrm{O}=$ $7,9,11,13,15$, and 17$)$. ( $\mathrm{g}$ and $\mathrm{h}$ ) Trends of $\mathrm{C}_{8}$ and $\mathrm{C}_{16}$ species as a function of $\mathrm{AP}$ reacted: $(\mathrm{g}) \mathrm{C}_{8}(\mathrm{H}=12$ and $14 ; \mathrm{O}=6,7$, and 8$)$ and $(\mathrm{h}) \mathrm{C}_{16} \mathrm{H}_{26} \mathrm{O}_{x}$ $(\mathrm{O}=9,10,11,12$, and 13$)$. All data are normalized to the highest HOM concentration in each class.

state. Then, we describe the implementation of the mechanistic scheme in a kinetic model and present the simulation of the experiments. Finally, we use the model to further constrain kinetic parameters from the experimental data.

4.1. HOM Products. We conducted the experiments under neutral (natural ions scavenged) and GCR (natural ions present) conditions. Because we did not observe any relevant differences in terms of chemistry between the two types of experiments, we use both data sets in our mechanistic analysis without differentiation. In our analysis, we focus on the dependence and relative contributions of identified HOMs upon the amount of reacted $\mathrm{AP}\left(\mathrm{AP}_{\text {react }}\right)$ by ozone and $\mathrm{OH}$ radicals. We identified around 300 different molecular formulas; most of the HOMs appeared as adducts with the nitrate anion $\left(\mathrm{NO}_{3}{ }^{-}\right)$, and a small fraction appeared as adducts with the nitrate dimer anion $\left(\mathrm{HNO}_{3} \cdot \mathrm{NO}_{3}{ }^{-}\right)$. We divide the identified 
compounds into monomers with 10 or fewer $(8-10)$ carbon atoms $\left(\mathrm{C}_{10}\right)$ and dimers with $16-20$ carbon atoms. Figure 1a shows the dependence of the total HOM concentration and their $\mathrm{O} / \mathrm{C}$ upon the amount of $\mathrm{AP}_{\text {react }}$. We corrected $\mathrm{HOM}$ concentrations for wall and condensational loss, assuming the same maximal loss rates for all compounds. A stronger than linear increase of the total HOM concentration with higher $\mathrm{AP}_{\text {react }}$ is evident, while the average $\mathrm{O} / \mathrm{C}$ decreases from 0.81 to 0.70 from the lowest to the highest $\mathrm{AP}_{\text {react }}$ concentration. The average $\mathrm{H} / \mathrm{C}$ stays unchanged at 1.5 . The decrease of the average $\mathrm{O} / \mathrm{C}$ indicates that a higher fraction of the less oxygenated HOMs is formed with increasing $\mathrm{AP}_{\text {react }}$ as a result of faster bimolecular termination reactions (reactions $\mathrm{R} 3$ and R4) interrupting the autoxidation chain. Because the less oxygenated HOMs have a higher volatility and partition less to the particles, a higher fraction of HOMs might be observed in the gas phase at high $\mathrm{AP}_{\text {react }}$.

4.1.1. Relative Contributions of HOM Classes. We grouped the $\mathrm{C}_{10}$ and $\mathrm{C}_{20}$ compounds according to their number of hydrogen atoms, while we classified the products from fragmentation pathways only with respect to their carbon number, i.e., $\mathrm{C}_{8}$ and $\mathrm{C}_{9}$ for monomers and $\mathrm{C}_{16}-\mathrm{C}_{19}$ for dimers. Figure $1 \mathrm{~b}$ illustrates the relative contribution of these classes at different $\mathrm{AP}_{\text {react. }}$. The fraction of the $\mathrm{C}_{10}$ compounds and radicals decreases from 65 to $33 \%$ with increasing $A P_{\text {react }}$, while the $C_{20}$ dimers always comprise between 10 and $19 \%$. On the other hand, the contribution of the compounds from the fragmentation pathways strongly increases with $\mathrm{AP}_{\text {react }}$. While the $\mathrm{C}_{9}$ monomer fraction stays roughly constant, the $\mathrm{C}_{8}$ fraction grows from 3 to $10 \%$ with increasing $\mathrm{AP}_{\text {react }}$. Similarly, the corresponding $\mathrm{C}_{16}-\mathrm{C}_{19}$ fraction of the dimers rises from 8 to $28 \%$. HOM clustering with a nitric acid dimer $\left(\mathrm{HNO}_{3} \cdot \mathrm{NO}_{3}{ }^{-}\right)$ accounts for $8-11 \%$ of the detected signal.

4.1.2. Variability of HOMs within Classes. In the following, we present the contributions of individual species within a HOM class as a function of $\mathrm{AP}_{\text {react }}$ Each HOM is shown as its ratio to the total HOM concentration normalized to the highest ratio among the different experiments. Panels a-d of Figure 2 show the $\mathrm{C}_{10}$ classes with 14 and 15 hydrogen atoms each separated into subclasses with even and odd oxygen atom numbers (from 6 to 12 and from 5 to 11 , respectively). The contribution of the $\mathrm{C}_{10} \mathrm{H}_{15} \mathrm{O}_{\text {even }}$ and $\mathrm{C}_{10} \mathrm{H}_{14} \mathrm{O}_{\text {odd }}$ species, which have not undergone an alkoxy autoxidation sequence (Table 1 ), generally decreases with increasing $\mathrm{AP}_{\text {react }}$. The decline is higher for the species with a higher oxygen content. This indicates that, with an increasing peroxy radical concentration, peroxy-peroxy radical reactions do prevent autoxidation from reaching a very high oxygen content.

The classes $\mathrm{C}_{10} \mathrm{H}_{14} \mathrm{O}_{\text {even }}$ and $\mathrm{C}_{10} \mathrm{H}_{15} \mathrm{O}_{\text {odd }}$ are formed from products via the alkoxy channel (Table 1 ). Here, the trends are variable. In both classes, the species with the highest oxygen number, $\mathrm{C}_{10} \mathrm{H}_{15} \mathrm{O}_{11}$ and $\mathrm{C}_{10} \mathrm{H}_{14} \mathrm{O}_{12}$, also decrease with rising $\mathrm{AP}_{\text {react }}$. The other species in the $\mathrm{C}_{10} \mathrm{H}_{14} \mathrm{O}_{\text {even }}$ class increase first and then decline with higher $\mathrm{AP}_{\text {react }}$. This shows the increasing importance of the alkoxy autoxidation pathway at higher ozonolysis rates, whereby the formation of the very highly oxygenated compounds is again inhibited by peroxy-peroxy radical reactions. In the $\mathrm{C}_{10} \mathrm{H}_{15} \mathrm{O}_{\text {odd }}$ class, the less oxygenated species do not show a clear trend. Panels e and $f$ of Figure 2 present the dimers with even and odd oxygen numbers $\left(\mathrm{C}_{20} \mathrm{H}_{30} \mathrm{O}_{\text {even }}\right.$ and $\left.\mathrm{C}_{20} \mathrm{H}_{30} \mathrm{O}_{\text {odd }}\right)$. The most oxygenated species $\left(\mathrm{C}_{20} \mathrm{H}_{30} \mathrm{O}_{16}\right.$ and $\left.\mathrm{C}_{20} \mathrm{H}_{30} \mathrm{O}_{18}\right)$ decrease with increasing $A \mathrm{P}_{\text {react }}$ while the least oxygenated species $\left(\mathrm{C}_{20} \mathrm{H}_{30} \mathrm{O}_{8}\right)$ increase. The
$\mathrm{C}_{20} \mathrm{H}_{30} \mathrm{O}_{10,12,14}$ compounds first increase with $\mathrm{AP}_{\text {react }}$ and then exhibit a slight decline. These trends of the dimers reflect the trends of the $\mathrm{C}_{10} \mathrm{H}_{15} \mathrm{O}_{\text {even }}$ radicals, which show a fast decline of the most oxygenated species. Because the $\mathrm{C}_{10} \mathrm{H}_{15} \mathrm{O}_{\text {odd }}$ concentrations are lower, their recombination contributes less to $\mathrm{C}_{20} \mathrm{H}_{30} \mathrm{O}_{\text {even }}$. The odd oxygen dimers in Figure $2 \mathrm{f}$ generally increase with increasing $\mathrm{AP}_{\text {react }}$ Panels $\mathrm{g}$ and $\mathrm{h}$ of Figure 2 illustrate two classes of product species that arise from the fragmentation pathway. As expected, both the $\mathrm{C}_{8} \mathrm{H}_{y} \mathrm{O}_{z}$ as well as $\mathrm{C}_{16} \mathrm{H}_{26} \mathrm{O}_{z}$ species generally increase with $\mathrm{AP}_{\text {react }}$ as a result of the growing importance of the alkoxy pathway (see also Figure 1b).

4.2. Master Chemical Mechanism HOM Add-on. We extended the near-explicit Master Chemical Mechanism 3.3.1 (MCM) with a chemical scheme for HOMs based on the mechanism described above. In a first step, the MCM forms two Criegee structures APINOOA and APINOOB from a different cleavage of the ozonide. APINOOA decays to two peroxy radical species of chemical formula $\mathrm{C}_{10} \mathrm{H}_{15} \mathrm{O}_{4}$, labeled $\mathrm{C} 107 \mathrm{O} 2$ and $\mathrm{C} 109 \mathrm{O} 2$ in the MCM. However, APINOOB decays to a $\mathrm{C}_{9}$ peroxy radical and pinonaldehyde. Therefore, we also introduced a $\mathrm{C}_{10} \mathrm{H}_{15} \mathrm{O}_{4}$ peroxy radical as a product of the APINOOB branch. Starting from these $\mathrm{C}_{10} \mathrm{H}_{15} \mathrm{O}_{4}$ peroxy radicals, we extended the mechanism by including autoxidation reactions, forming products with up to 10 oxygen atoms. The kinetic model includes 29 new chemical species and 57 new chemical reactions, which are derived from the generic reaction schemes discussed in Section 3 and shown in Schemes S1 and S2 of the Supporting Information). Alkoxy radical reactions account for hydrogen shift (reaction R6a), ring opening (reaction R6b) and fragmentation of the carbon chain (reaction R6c) (Scheme S1 of the Supporting Information). We added products of a fragmentation step (peroxy radicals) to an existing MCM species with less than 10 carbon atoms to preserve the carbon balance. Our model does not include $\mathrm{C}_{8}$ and $\mathrm{C}_{9} \mathrm{HOM}$ monomers. Neither do we implement HOM formation from the $\mathrm{OH}$ attack. We set the reaction rate constants (reactions $\mathrm{R} 3$ and $\mathrm{R} 4$ ) in the autoxidation mechanism based on generic rate constants available in the MCM database for similar reactions or derived from experimental data when available.

We ran the model with the conditions of the CLOUD chamber as detailed in the Supporting Information. In the simulations, the $\mathrm{HO}_{2}$ concentration increases from $3.9 \times 10^{6}$ to $8.0 \times 10^{6}$ molecules $\mathrm{cm}^{-3}$, while $\mathrm{RO}_{2}$ rises from $2.1 \times 10^{8}$ to 9.9 $\times 10^{9}$ molecules $\mathrm{cm}^{-3}$ with increasing $\mathrm{AP}_{\text {react }}$ (Figure $\mathrm{S} 1$ of the Supporting Information). Thus, $\mathrm{RO}_{2} / \mathrm{HO}_{2}$ increases from 43 to a maximum of 1244 . In the MCM, the reaction rate constant for a generic $\mathrm{RO}_{2}-\mathrm{HO}_{2}$ reaction is $3.1 \times 10^{-11} \mathrm{~cm}^{3}$ molecule ${ }^{-1} \mathrm{~s}^{-1}$, while the generic reaction rate constants for $\mathrm{RO}_{2}-\mathrm{RO}_{2}$ reactions range from $1.0 \times 10^{-11}$ to $9.2 \times 10^{-14} \mathrm{~cm}^{3}$ molecule ${ }^{-1} \mathrm{~s}^{-1}$ for peroxyacid and tertiary carbon peroxy radicals, respectively. This implies that, at low $\mathrm{AP}_{\text {react }} \mathrm{RO}_{2}-\mathrm{HO}_{2}$ may still be competitive with $\mathrm{RO}_{2}-\mathrm{RO}_{2}$ radical reactions, while at high $\mathrm{AP}_{\text {react }}$ the latter reaction becomes the dominant bimolecular termination reaction of peroxy radicals.

Figure 3 shows the results of the simulations for the same HOM classes as presented in panels a-d of Figure 2 from the measurements. The simulated trends of $\mathrm{C}_{10} \mathrm{H}_{14} \mathrm{O}_{\text {even, }}$, $\mathrm{C}_{10} \mathrm{H}_{14} \mathrm{O}_{\text {odd }}$ and $\mathrm{C}_{10} \mathrm{H}_{15} \mathrm{O}_{\text {even }}$ are in good agreement with the measurements. Species produced directly from the autoxidation mechanism $\mathrm{C}_{10} \mathrm{H}_{14} \mathrm{O}_{\text {odd }}$ and $\mathrm{C}_{10} \mathrm{H}_{15} \mathrm{O}_{\text {even }}$ (Scheme $\mathrm{S} 1$ of the Supporting Information) decline as a function of $\mathrm{AP}_{\text {react }}$. The decrease is stronger for more oxidized $\mathrm{C}_{10} \mathrm{H}_{14} \mathrm{O}_{9}$ and $\mathrm{C}_{10} \mathrm{H}_{15} \mathrm{O}_{10}$. HOMs produced via an alkoxy radical step (Scheme S2 of the 

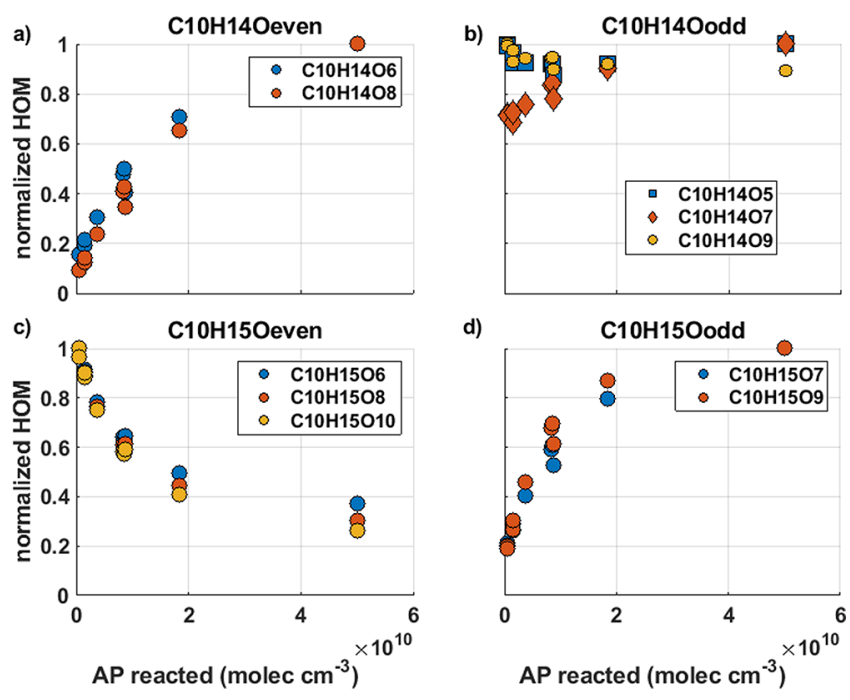

Figure 3. Modeled $\mathrm{C}_{10}$ monomers among classes and within a class as a function of AP reacted: (a) $\mathrm{C}_{10} \mathrm{H}_{14} \mathrm{O}_{\text {even }}(\mathrm{O}=6$ and 8$)$, (b) $\mathrm{C}_{10} \mathrm{H}_{14} \mathrm{O}_{\text {odd }}$ $\left(\mathrm{O}=5,7\right.$, and 9), (c) $\mathrm{C}_{10} \mathrm{H}_{15} \mathrm{O}_{\text {even }}(\mathrm{O}=6,8$, and 10), and (d) $\mathrm{C}_{10} \mathrm{H}_{15} \mathrm{O}_{\text {odd }}(\mathrm{O}=7$ and 9$)$. Data are normalized to the highest HOM concentration in each class.

Supporting Information) instead show a positive trend as a function of reacted $\mathrm{AP}$, and no clear effect on the oxygen number is seen. The increasing concentration of $\mathrm{RO}_{2}$ species seems to promote the alkoxy radical autoxidation route. In the case of $\mathrm{C}_{10} \mathrm{H}_{15} \mathrm{O}_{\text {odd }}$, the simulation shows a similar but much more pronounced increase compared to the measurements (Figure $2 \mathrm{~d}$ ). Figure 4 presents a comparison of measured and modeled

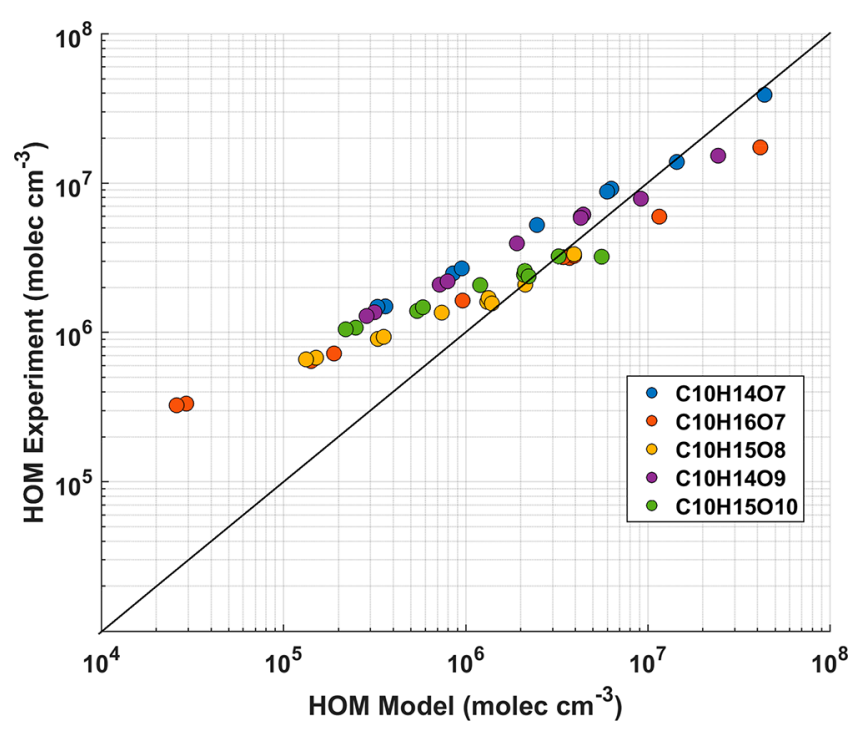

Figure 4. Comparison between modeled ( $x$ axis) and measured ( $y$ axis) $\mathrm{HOM}$ concentrations. The main HOM monomer species $\mathrm{C}_{10} \mathrm{H}_{14} \mathrm{O}_{7}$, $\mathrm{C}_{10} \mathrm{H}_{16} \mathrm{O}_{7}$, and $\mathrm{C}_{10} \mathrm{H}_{14} \mathrm{O}_{9}$ and $\mathrm{HOM}$ radicals $\mathrm{C}_{10} \mathrm{H}_{15} \mathrm{O}_{8}$ and $\mathrm{C}_{10} \mathrm{H}_{15} \mathrm{O}_{10}$ are shown.

$\mathrm{HOM}$ concentrations for the species $\mathrm{C}_{10} \mathrm{H}_{14} \mathrm{O}_{\text {odd }}\left(\mathrm{O}_{7}\right.$ and $\left.\mathrm{O}_{9}\right)$, $\mathrm{C}_{10} \mathrm{H}_{16} \mathrm{O}_{\text {odd }}\left(\mathrm{O}_{7}\right)$, and the radicals $\mathrm{C}_{10} \mathrm{H}_{15} \mathrm{O}_{\text {even }}\left(\mathrm{O}_{8}\right.$ and $\left.\mathrm{O}_{10}\right)$. Overall, the relative contributions and trends of these HOMs with $\mathrm{AP}_{\text {react }}$ were simulated rather well. However, the model tends to underestimate the measured HOM concentration for low $\mathrm{AP}_{\text {react }}$ while at high $\mathrm{AP}_{\text {react, }}$ the model overestimates the HOM concentration. This may be due to the fact that the model does not consider all possible reaction pathways. The systematic trend of the deviation from the 1:1 line may also indicate that the MCM model does not correctly simulate the total $\mathrm{RO}_{2}$ concentration. For example, a narrower range of $\mathrm{RO}_{2}$ concentrations from low to high $\mathrm{AP}_{\text {react }}$ could bring the dependence of $\mathrm{HOMs}$ upon $\mathrm{AP}_{\text {react }}$ in better agreement with the measurements.

4.3. Kinetic Analysis. 4.3.1. $\mathrm{RO}_{2}$ Reactions. According to Table 1, $\mathrm{C}_{10} \mathrm{H}_{14} \mathrm{O}_{\text {odd }}$ compounds are exclusively formed from the primary peroxy radicals $\mathrm{C}_{10} \mathrm{H}_{15} \mathrm{O}_{\text {even }}$, while $\mathrm{C}_{10} \mathrm{H}_{14} \mathrm{O}_{\text {even }}$ compounds arise from the $\mathrm{C}_{10} \mathrm{H}_{15} \mathrm{O}_{\text {odd }}$ radicals, which have cycled through an alkoxy radical path. The three pathways to $\mathrm{C}_{10} \mathrm{H}_{14} \mathrm{O}_{x}$ are either via unimolecular decomposition of the peroxy radical (reaction $\mathrm{R} 2$ ) or via reaction of the $\mathrm{C}_{10} \mathrm{H}_{15} \mathrm{O}_{x}$ radicals with any other $\mathrm{RO}_{2}$ (reaction $\mathrm{R} 4$ ). Therefore, a dependence of $\mathrm{C}_{10} \mathrm{H}_{14} \mathrm{O}_{x}$ upon the $\mathrm{RO}_{2}$ concentration should be seen. Indeed, for all $\mathrm{C}_{10} \mathrm{H}_{14} \mathrm{O}_{x} / \mathrm{C}_{10} \mathrm{H}_{15} \mathrm{O}_{x}$ pairs a good correlation with total modeled $\mathrm{RO}_{2}$ is obtained, as seen in panels $\mathrm{a}$ and $\mathrm{b}$ of Figure 5. The same can also be observed for the dependence of $\mathrm{C}_{10} \mathrm{H}_{16} \mathrm{O}_{\text {odd }} / \mathrm{C}_{10} \mathrm{H}_{15} \mathrm{O}_{\text {even }}$ on $\mathrm{RO}_{2}$ (Figure $5 \mathrm{c}$ ). This confirms that the reaction channel with $\mathrm{HO}_{2}$ (reaction $\mathrm{R} 3 \mathrm{a}$ ) is a minor pathway, as expected from the high modeled $\mathrm{RO}_{2} / \mathrm{HO}_{2}$ (see Figure $\mathrm{S} 1 \mathrm{~b}$ of the Supporting Information).

From the slope and intercept of a linear fit to the displayed data, the reaction rate constants for the reaction $\mathrm{R}^{\prime} \mathrm{O}_{2}+\mathrm{RO}_{2} \rightarrow$ $\mathrm{R}_{\mathrm{H}} \mathrm{O}$ (or $\mathrm{R}^{\prime} \mathrm{O}_{2}+\mathrm{RO}_{2} \rightarrow \mathrm{ROH}$ for panel c) $\left(k_{\mathrm{R} 4 \mathrm{a}}\right)$ and the unimolecular decomposition $\left(k_{\mathrm{R} 2}\right)$ can be derived, i.e., $k_{\mathrm{R} 4 \mathrm{a}}=$ slope $\times k_{\text {wall }}\left(k_{\text {wall }}\right.$ being the wall loss rate $)$, and $k_{\mathrm{R} 2}=$ intercept $\times$ $k_{\text {wall }}$ (see the Supporting Information). Table 2 summarizes the reaction rate constants using a CLOUD chamber typical wall loss rate for HOM monomers of $1.1 \times 10^{-3} \mathrm{~s}^{-1}$ for the three different cases. ${ }^{7}$ The values for $k_{\mathrm{R} 4 \mathrm{a}}$ are in the range from $7.9 \times$ $10^{-12}$ to $5.0 \times 10^{-14} \mathrm{~cm}^{-3}$ molecule $\mathrm{s}^{-1}$, which spans a range similar to the generic reaction rate constants for such reactions in the MCM. The unimolecular decomposition rate constants are in the range of $(0.6-7) \times 10^{-3} \mathrm{~s}^{-1}$. It has to be noted that these rate constants do not represent one specific reaction but rather are (weighted) averages over several reaction pathways.

4.3.2. Dimer Formation. It is thought that dimers are formed by the recombination of two $\mathrm{RO}_{2}$ radicals (reaction $\mathrm{R} 4 \mathrm{c}$ ). The rate of dimer formation would then follow eq 1.

$$
\frac{\mathrm{d}\left[\mathrm{ROOR}^{\prime}\right]}{\mathrm{d} t}=k_{\mathrm{R} 4 \mathrm{c}}\left[\mathrm{RO}_{2}\right]\left[\mathrm{RO}_{2}^{\prime}\right]-k_{\text {wall }}\left[\mathrm{ROOR}^{\prime}\right]
$$

We neglect the dilution rate because it is 10 times smaller than the wall loss rate. Under steady-state conditions, the concentrations of the $\mathrm{C}_{20}$ dimers are given by eqs 2 and 3, whereby $[x]$ denotes $\mathrm{C}_{10} \mathrm{H}_{15} \mathrm{O}_{x}$ with the corresponding number of oxygen atoms. We summarize the possible radical-radical recombinations, yielding a specific dimer in Table S2 of the Supporting Information.

$$
\begin{aligned}
{\left[\mathrm{C}_{20} \mathrm{H}_{30} \mathrm{O}_{2 x-2}\right]_{\text {even }}=} & \left(k_{1}[x][x]+k_{2}[x-1][x+1]\right. \\
& \left.+k_{3}[x-2][x+2] \ldots\right) / k_{\text {wall }} \\
{\left[\mathrm{C}_{20} \mathrm{H}_{30} \mathrm{O}_{2 x-1}\right]_{\text {odd }}=} & \left(k_{1}[x][x+1]+k_{2}[x-1][x+2]\right. \\
& \left.+k_{3}[x-2][x+3] \ldots\right) / k_{\text {wall }}
\end{aligned}
$$

Dimers with 14,15 , and 16 oxygen atoms are formed by four $\mathrm{RO}_{2}-\mathrm{RO}_{2}$ combinations, while for dimers with 17 and 18 oxygen atoms, only three combinations are possible. We calculated reaction rate constants from eq 2 and 3 with a non- 

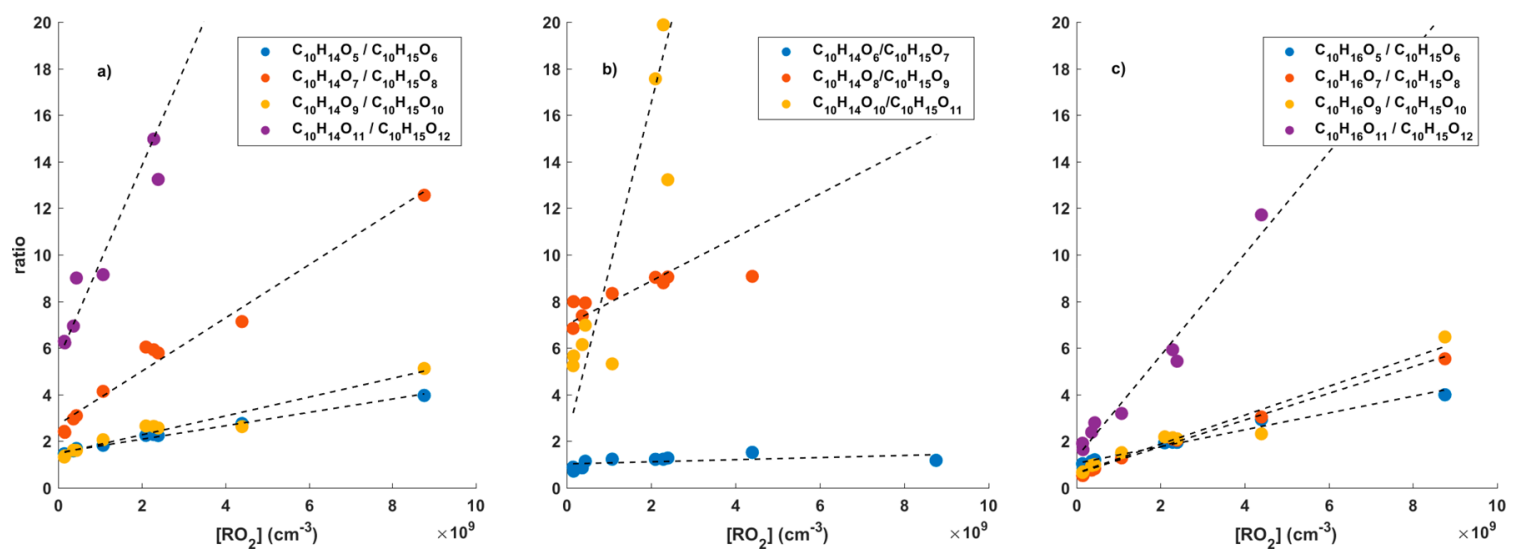

Figure 5. Ratios of closed-shell HOM species to their precursor peroxy radical as a function of the total modeled peroxy radical concentration: (a) $\mathrm{C}_{10} \mathrm{H}_{14} \mathrm{O}_{\text {odd }} / \mathrm{C}_{10} \mathrm{H}_{15} \mathrm{O}_{\text {even }}$ ratio, (b) $\mathrm{C}_{10} \mathrm{H}_{14} \mathrm{O}_{\text {even }} / \mathrm{C}_{10} \mathrm{H}_{15} \mathrm{O}_{\text {odd }}$ ratio, and (c) $\mathrm{C}_{10} \mathrm{H}_{16} \mathrm{O}_{\text {odd }} / \mathrm{C}_{10} \mathrm{H}_{15} \mathrm{O}_{\text {even }}$ ratio. Black dashed lines show the linear least squares fits.

Table 2. Reaction Rate Constants of HOM Monomer

Formation via the Reactions R4a and R2 as Derived from Linear Regression Fits to the Data Shown in Figure 5 and HOM Dimer Formation as Described in Section 4.3.2

\begin{tabular}{cccc}
$\mathrm{R}_{\mathrm{H}} \mathrm{O} / \mathrm{RO}_{2}$ & $k_{\mathrm{R} 4 \mathrm{a}}\left(\mathrm{cm}^{3} \mathrm{~s}^{-1}\right)$ & $k_{\mathrm{R} 2}\left(\mathrm{~s}^{-1}\right)$ & $k_{\text {dimer }}\left(\mathrm{cm}^{3} \mathrm{~s}^{-1}\right)$ \\
$\mathrm{C}_{10} \mathrm{H}_{14} \mathrm{O}_{5} / \mathrm{C}_{10} \mathrm{H}_{15} \mathrm{O}_{6}$ & $3.0 \times 10^{-13}$ & $1.4 \times 10^{-3}$ & \\
$\mathrm{C}_{10} \mathrm{H}_{14} \mathrm{O}_{7} / \mathrm{C}_{10} \mathrm{H}_{15} \mathrm{O}_{8}$ & $1.2 \times 10^{-12}$ & $2.5 \times 10^{-3}$ & \\
$\mathrm{C}_{10} \mathrm{H}_{14} \mathrm{O}_{9} / \mathrm{C}_{10} \mathrm{H}_{15} \mathrm{O}_{10}$ & $4.2 \times 10^{-13}$ & $1.4 \times 10^{-3}$ & \\
$\mathrm{C}_{10} \mathrm{H}_{14} \mathrm{O}_{11} / \mathrm{C}_{10} \mathrm{H}_{15} \mathrm{O}_{12}$ & $4.3 \times 10^{-12}$ & $5.1 \times 10^{-3}$ & \\
& & & \\
$\mathrm{C}_{10} \mathrm{H}_{14} \mathrm{O}_{6} / \mathrm{C}_{10} \mathrm{H}_{15} \mathrm{O}_{7}$ & $4.7 \times 10^{-14}$ & $1.0 \times 10^{-3}$ & \\
$\mathrm{C}_{10} \mathrm{H}_{14} \mathrm{O}_{8} / \mathrm{C}_{10} \mathrm{H}_{15} \mathrm{O}_{9}$ & $9.6 \times 10^{-13}$ & $6.5 \times 10^{-3}$ & \\
$\mathrm{C}_{10} \mathrm{H}_{14} \mathrm{O}_{10} / \mathrm{C}_{10} \mathrm{H}_{15} \mathrm{O}_{11}$ & $7.4 \times 10^{-12}$ & $1.9 \times 10^{-3}$ & \\
& & & \\
$\mathrm{C}_{10} \mathrm{H}_{16} \mathrm{O}_{5} / \mathrm{C}_{10} \mathrm{H}_{15} \mathrm{O}_{6}$ & $3.8 \times 10^{-13}$ & & \\
$\mathrm{C}_{10} \mathrm{H}_{16} \mathrm{O}_{7} / \mathrm{C}_{10} \mathrm{H}_{15} \mathrm{O}_{8}$ & $6.0 \times 10^{-13}$ & & \\
$\mathrm{C}_{10} \mathrm{H}_{16} \mathrm{O}_{9} / \mathrm{C}_{10} \mathrm{H}_{15} \mathrm{O}_{10}$ & $6.4 \times 10^{-13}$ & & \\
$\mathrm{C}_{10} \mathrm{H}_{16} \mathrm{O}_{11} / \mathrm{C}_{10} \mathrm{H}_{15} \mathrm{O}_{12}$ & $2.3 \times 10^{-12}$ & & \\
& & & $3.2 \times 10^{-10}$ \\
$\mathrm{C}_{20} \mathrm{H}_{30} \mathrm{O}_{14}$ & & & $2.3 \times 10^{-10}$ \\
$\mathrm{C}_{20} \mathrm{H}_{30} \mathrm{O}_{15}$ & & & $1.8-4.4 \times 10^{-10}$ \\
$\mathrm{C}_{20} \mathrm{H}_{30} \mathrm{O}_{16}$ & & & $0.8-1.6 \times 10^{-10}$ \\
$\mathrm{C}_{20} \mathrm{H}_{30} \mathrm{O}_{17}$ & & & \\
$\mathrm{C}_{20} \mathrm{H}_{30} \mathrm{O}_{18}$ & & & \\
\hline
\end{tabular}

negative linear least squares analysis (lsqnonneg from $\mathrm{MATLAB}^{39}$ ). In a first approach, we used all variables given in Table S2 of the Supporting Information. This produced some very high rate constants $\left(\gg 10^{-10} \mathrm{~cm}^{3}\right.$ molecule $\left.\mathrm{e}^{-1} \mathrm{~s}^{-1}\right)$ and zero values (Table S3 of the Supporting Information). The latter are due to pairs of variables with very high collinearity. Therefore, in a second approach, we neglected those reactions with rate constants much above $9 \times 10^{-10} \mathrm{~cm}^{3}$ molecule $\mathrm{e}^{-1} \mathrm{~s}^{-1}$ because they do not contribute much to the dimer concentration and improve only the fit. The rate constants obtained for the remaining reactions do not differ much from those fits with all reactions (Table S3 of the Supporting Information). This confirms that there are only one or two main $\mathrm{RO}_{2}$ combinations to the different dimers. This analysis reveals that the rate constants of the formation of highly oxygenated dimers appear to be extremely fast, in the range of $(0.8-9) \times 10^{-10} \mathrm{~cm}^{3}$ molecule $\mathrm{e}^{-1} \mathrm{~s}^{-1}$.

\section{DISCUSSION}

With $\mathrm{NO}_{3}$-CIMS, we identified about $300 \mathrm{HOM}$ products from the ozonolysis of AP as a result of an autoxidation mechanism that leads to a highly complex series of reactions and oxidation products. Because this type of mass spectrometry reveals only the chemical composition of the analyzed ions but not their chemical structure, many more HOM isomers may have been formed.

With increasing $\mathrm{AP}_{\text {react }}$, we observed a decreasing fraction of $\mathrm{C}_{10}$ and highly oxygenated monomers and dimers and a decrease of the $\mathrm{O} / \mathrm{C}$, while the fraction of compounds with $n_{\mathrm{C}}<10$ was increasing. While the production rate of peroxy radicals increases linearly, their loss rate as a result of the reaction of $\mathrm{RO}_{2}$ with $\mathrm{R}^{\prime} \mathrm{O}_{2}$ increases quadratically. This leads to a stronger competition between the peroxy-peroxy radical reaction and the autoxidation reaction, which interrupts the latter at an earlier stage and forms molecules with a lower degree of oxygenation. With a $\mathrm{RO}_{2}-\mathrm{RO}_{2}$ reaction rate constant of $10^{-12} \mathrm{~cm}^{3}$ molecule ${ }^{-1} \mathrm{~s}^{-1}$ (Table 2) and a $\mathrm{RO}_{2}$ concentration between $10^{9}$ and $10^{10} \mathrm{~cm}^{-3}$ (Figure S1 of the Supporting Information), the autoxidation rate constant should be in the range from $10^{-3}$ to $10^{-2} \mathrm{~s}^{-1}$ to compete. From quantum chemical calculations, rate coefficients for 1,5 and 1,6 hydrogen shift transfers in the order from $10^{-4}$ to $1 \mathrm{~s}^{-1}$ have been reported by Praske et al. ${ }^{40}$ and even faster rate coefficients in the range of $10 \mathrm{~s}^{-1}$ for autoxidation in alkylbenzenes have been reported by Wang et al. $^{24}$ Slow rate coefficients are calculated for 1,4 hydrogen shifts and hydrogen abstraction at a non-functionalized carbon atom. Fitting the kinetic parameters in the extended MCM model to the measured HOM concentrations for hydrogen shift transfer rate constants of around 1.3-2.4 $\times 10^{-1} \mathrm{~s}^{-1}$ (Table S4 of the Supporting Information) was obtained. Note that these are the average rate constants for the various possible $\mathrm{RO}_{2}$ stereoisomers. While such high rate constants have been calculated for functionalized peroxy radicals, the rigid four-member ring is expected to hinder hydrogen migration. ${ }^{35,41}$ It has been suggested that the rigid four-member ring needs to open for the autoxidation to proceed to high oxygen numbers. ${ }^{36}$ This most likely happens via the formation of an alkoxy radical, leading to a ring cleavage (reaction R6b in Scheme 1) and further autoxidation from there. This would imply a switch in the radical series to $\mathrm{C}_{10} \mathrm{H}_{15} \mathrm{O}_{\text {odd }}$. However, this is not observed here, and the $\mathrm{C}_{10} \mathrm{H}_{15} \mathrm{O}_{\text {even }}$ species are by far the main HOM radicals measured. Zhao et al. ${ }^{42}$ used flow tube experiments to develop 
an extended mechanism for HOM formation in the MCM. They determine an autoxidation rate of $3-10 \mathrm{~s}^{-1}$, whereby they allow only $10 \%$ of peroxy radicals from the ozonolysis to proceed along this pathway. Taken together, this comes close to the values used by us.

Assuming that the simulated $\mathrm{RO}_{2}$ concentrations are correct, we determined average reaction rate constants for the HOM$\mathrm{RO}_{2}-\mathrm{RO}_{2}$ reactions, leading to a carbonyl and alcohol product (reaction R4a) in the range of $(0.05-7) \times 10^{-12} \mathrm{~cm}^{3}$ molecule ${ }^{-1}$ $\mathrm{s}^{-1}$. These are compatible with rate constants measured for smaller primary peroxy radicals. ${ }^{43}$ We believe that these values are good estimates given the fact that the reaction almost exclusively occurs between $\mathrm{C}_{10} \mathrm{H}_{15} \mathrm{O}_{x}$ and a $\mathrm{RO}_{2}$ radical with a low degree of oxygenation or small size. The branching ratio to alkoxy radicals (reaction $\mathrm{R} 4 \mathrm{~b}$ ) is reported to vary from 10 to $90 \%$. These have a lower barrier for fragmentation when there is a neighboring oxygen-containing functional group ${ }^{44}$ and could thus explain the increase of fragmentation products. In addition, at low $\mathrm{AP}_{\text {react }}$, the reaction of $\mathrm{HO}_{2}$ with peroxy radicals leading to hydroperoxides (reaction R3a) does contribute to HOM formation, while at high $\mathrm{AP}_{\text {react, }}$ this pathway is negligible as a result of the high $\mathrm{RO}_{2} / \mathrm{HO}_{2}$ in the chamber. Furthermore, we also estimated the reaction rate constants of the dimer formation assuming the mechanism given by reaction $\mathrm{R} 4 \mathrm{c}$. We found very high rate coefficients in the range of $(1-9) \times 10^{-10} \mathrm{~cm}^{3}$ molecule ${ }^{-1} \mathrm{~s}^{-1}$. We determined the highest possible collision rate of such large molecules to be $9 \times 10^{-10} \mathrm{~cm}^{3}$ molecule ${ }^{-1} \mathrm{~s}^{-1}$ (see the Supporting Information). We restricted our analysis only to the dimers with high oxygen numbers, for which we expect that the contributing peroxy radicals are well-measured with $\mathrm{NO}_{3}-\mathrm{CIMS}$. However, because there is currently no method to calibrate the instrument for such compounds, there remains some uncertainty. It has to be noted that an uncertainty in the measured concentration by a factor of 2 would change the rate coefficient by a factor of 4 . Recently, the reaction rate constants of such accretion reactions between HOM peroxy radicals formed through the $\mathrm{OH}$ oxidation of 1,3,5-trimethylbenzene and AP ozonolysis have been determined. ${ }^{25,45}$ These authors also found rate constants close to $(1-2) \times 10^{-10}$ and $(3.7-7.9) \times 10^{-10} \mathrm{~cm}^{3}$ molecule ${ }^{-1} \mathrm{~s}^{-1}$, respectively. Several dimers with less than 20 carbon atoms, which are formed from HOMs with $n_{\mathrm{C}}<10$, were also observed. In the mechanism of Zhao et al., the $\mathrm{RO}_{2}$ radicals are lumped together. $\mathrm{RO}_{2}$ cross reaction rate constants had to be constrained to $(0.75-2) \times$ $10^{-12} \mathrm{~cm}^{-3}$ molecule $\mathrm{s}^{-1}$, with a dimer branching ratio of 0.04 . While our rate constants $k_{\mathrm{R} 4 \mathrm{a}}$ for the $\mathrm{HOM}-\mathrm{RO}_{2}-\mathrm{RO}_{2}$ are in a similar range, the $\mathrm{HOM}-\mathrm{RO}_{2}$ cross reactions, yielding highly oxygenated dimers, have much higher rate constants $\left(k_{\text {dimer }}\right)$. The accretion rate constants for smaller and less functionalized peroxy radicals have been found to be much slower. ${ }^{25,43}$ This indicates that the structure and functionality of $\mathrm{HOM}-\mathrm{RO}_{2}$ seems to be very critical regarding the reaction pathway and rate. Detailed studies on these parameters are strongly needed.

The atmospheric relevance of this chemistry is a crucial issue. The formation of HOM monomers, which dominate the products that we observe, only depends upon the competition between the unimolecular $\mathrm{RO}_{2}$ chemistry and any termination reactions. This will, if anything, be even more favorable to HOM formation in the atmosphere than in these chamber experiments. However, production of ROOR dimers may be key to the role of HOM in "pure biogenic" nucleation. ${ }^{7}$ Very often, the presence of significant $\mathrm{RO}_{2}+\mathrm{RO}_{2}$ chemistry in a chamber experiment is a sign that the chamber chemistry has diverged from typical atmospheric conditions. There are two reasons for this. First, the atmospheric $\mathrm{RO}_{2} / \mathrm{HO}_{2}$ is thought to be significantly less than 1 (on the order of $0.1-0.2$ ). ${ }^{46}$ The reason is that reactions of $\mathrm{OH}$ with oxygenated organics ( $\mathrm{CO}$ being the most obvious) tend to lead directly to $\mathrm{HO}_{2}$ rather than first producing $\mathrm{RO}_{2}$ and that chemistry tends to be underrepresented in chamber experiments, where chambers are charged with hydrocarbons. Second, $\mathrm{RO}_{2}+\mathrm{RO}_{2}$ reactions for smaller and less oxygenated carbon backbones tend to be slow compared to either $\mathrm{RO}_{2}+\mathrm{HO}_{2}$ or $\mathrm{RO}_{2}+\mathrm{NO}$, which both occur for roughly 1 in 10 collisions (with a rate constant near $10^{-11} \mathrm{~cm}^{3}$ molecule ${ }^{-1} \mathrm{~s}^{-1}$ ). However, as we have shown, the $\mathrm{RO}_{2}+\mathrm{RO}_{2}$ dimerization reactions that are responsible for ROOR production are roughly 10 times faster than the more conventional $\mathrm{RO}_{2}+\mathrm{HO}_{2}$ or $\mathrm{RO}_{2}+\mathrm{NO}$ termination reactions and will therefore be important under typical atmospheric conditions (even at a relatively high $\mathrm{NO}$ concentration).

\section{CONCLUSION}

In this work, we show that the HOM formation from AP ozonolysis cannot be described as a linear process. While the production rate of peroxy radicals increases linearly, their loss rate as a result of the reaction of $\mathrm{RO}_{2}$ with $\mathrm{RO}_{2}$ increases quadratically. This leads to a stronger competition between the peroxy-peroxy radical reaction and the autoxidation reaction, which interrupts the latter at an earlier stage and forms molecules with a lower degree of oxygenation. One pathway of the peroxy-peroxy radical reaction leads to alkoxy radicals, which can fragment, explaining the increase of fragmentation products. This change in composition of HOMs, mainly the decrease of the very highly oxygenated compounds with extremely low volatility, may have consequences on NPF and early growth of particles. Additional degrees of complexity can be imagined when other chemical species come into play. Different oxidation regimes and the presence of $\mathrm{NO}_{x}$ translate to more players in the radical reaction pool. It may not be allowed to linearly extrapolate high-concentration experiments to lower concentrations without proper parametrization of the HOMs.

\section{ASSOCIATED CONTENT}

\section{Supporting Information}

The Supporting Information is available free of charge on the ACS Publications website at DOI: 10.1021/acsearthspacechem.9b00035.

Description of the experimental setup and mass spectrometer, list of experiments (Table S1), information on the development of the MCM kinetic model add-on, evaluation of the HOM collision rate, and derivation of reaction rate constants (Tables S2-S4), graphical presentations of the autoxidation schemes (Schemes S1-S3) and radical fragmentation (Schemes S4 and S5), and simulated $\mathrm{RO}_{2}$ and $\mathrm{HO}_{2}$ concentrations (Figure S1) (PDF)

\section{AUTHOR INFORMATION}

\section{Corresponding Author}

*E-mail: josef.dommen@psi.ch.

ORCID

Ugo Molteni: 0000-0002-1623-1933

Federico Bianchi: 0000-0003-2996-3604

Jonathan Duplissy: 0000-0001-8819-0264 
Simone M. Pieber: 0000-0002-5674-6640

Armin Hansel: 0000-0002-1062-2394

Josef Dommen: 0000-0002-0006-0009

\section{Present Addresses}

${ }^{\text {a }}$ Christopher R. Hoyle: Institute for Atmospheric and Climate Science, ETH Zurich, 8092 Zürich, Switzerland.

${ }^{\mathrm{b}}$ Martin Breitenlechner: John A. Paulson School of Engineering and Applied Sciences, Harvard University, Cambridge, Massachusetts 02138, United States.

${ }^{\mathrm{c}}$ Sophia Brilke: Faculty of Physics, University of Vienna, 1090 Vienna, Austria.

${ }^{\mathrm{d}}$ Simone M. Pieber: Laboratory for Air Pollution and Environmental Technology (Empa), CH-8600 Dübendorf, Switzerland. ${ }^{\mathrm{e}}$ Christina Williamson: Cooperative Institute for Research in Environmental Sciences, University of Colorado, Boulder, Colorado 80309, United States.

${ }^{f}$ Christina Williamson: Earth System Research Laboratory, National Oceanic and Atmospheric Administration (NOAA), Boulder, Colorado 80305, United States.

\section{Notes}

The authors declare no competing financial interest.

\section{ACKNOWLEDGMENTS}

The tofTools team is acknowledged for providing tools for mass spectrometry analysis. The authors thank CERN for supporting CLOUD with technical and financial resources. This research has received funding from the EC Seventh Framework Programme (Marie Curie Initial Training Network "CLOUDITN” 215072, MC-ITN “CLOUD-TRAIN” 316662, ERC-StGATMOGAIN 278277, and ERC-Advanced "ATMNUCLE" Grant 227463), the German Federal Ministry of Education and Research (Projects 01LK0902A and 01LK1222A), the Swiss National Science Foundation (Projects 200020_152907, 200020 172602, and 20FI20 149002), the Academy of Finland Center of Excellence Programme (Project 1118615, LASTU Project 135054), the Nessling Foundation, the EU's Horizon 2020 Research and Innovation Programme under the Marie Sklodowska-Curie (656994), the Portuguese Foundation for Science and Technology (Project CERN/FP/116387/ 2010), the Presidium of the Russian Academy of Sciences and Russian Foundation for Basic Research (Grants 08-02-91006CERN and 12-02-91522-CERN), Dreyfus Award EP-11-117, the Davidow Foundation, the U.S. National Science Foundation (Grants AGS1136479, AGS1447056, AGS1439551, and CHE1012293), and the U.S. Department of Energy (Grant DE-SC00014469).

\section{REFERENCES}

(1) Sindelarova, K.; Granier, C.; Bouarar, I.; Guenther, A.; Tilmes, S.; Stavrakou, T.; Müller, J.-F.; Kuhn, U.; Stefani, P.; Knorr, W. Global Data Set of Biogenic VOC Emissions Calculated by the MEGAN Model over the Last 30 Years. Atmos. Chem. Phys. 2014, 14 (17), 93179341 .

(2) Atkinson, R.; Arey, J. Atmospheric Degradation of Volatile Organic Compounds. Chem. Rev. 2003, 103 (12), 4605-4638.

(3) Jokinen, T.; Sipilä, M.; Junninen, H.; Ehn, M.; Lönn, G.; Hakala, J.; Petäjä, T.; Mauldin, R. L.; Kulmala, M.; Worsnop, D. R. Atmospheric Sulphuric Acid and Neutral Cluster Measurements Using CI-APi-TOF. Atmos. Chem. Phys. 2012, 12 (9), 4117-4125.

(4) Ehn, M.; Thornton, J. a.; Kleist, E.; Sipilä, M.; Junninen, H.; Pullinen, I.; Springer, M.; Rubach, F.; Tillmann, R.; Lee, B.; et al. A Large Source of Low-Volatility Secondary Organic Aerosol. Nature 2014, 506 (7489), 476-479.
(5) Crounse, J. D.; Knap, H. C.; Ørnsø, K. B.; Jørgensen, S.; Paulot, F.; Kjaergaard, H. G.; Wennberg, P. O. Atmospheric Fate of Methacrolein. 1. Peroxy Radical Isomerization Following Addition of $\mathrm{OH}$ and $\mathrm{O}_{2}$. J. Phys. Chem. A 2012, 116 (24), 5756-5762.

(6) Crounse, J. D.; Nielsen, L. B.; Jørgensen, S.; Kjaergaard, H. G.; Wennberg, P. O. Autoxidation of Organic Compounds in the Atmosphere. J. Phys. Chem. Lett. 2013, 4 (20), 3513-3520.

(7) Kirkby, J.; Duplissy, J.; Sengupta, K.; Frege, C.; Gordon, H.; Williamson, C.; Heinritzi, M.; Simon, M.; Yan, C.; Almeida, J.; et al. Ion-Induced Nucleation of Pure Biogenic Particles. Nature 2016, 533 (7604), 521-526.

(8) Stolzenburg, D.; Fischer, L.; Vogel, A. L.; Heinritzi, M.; Schervish, M.; Simon, M.; Wagner, A. C.; Dada, L.; Ahonen, L. R.; Amorim, A.; et al. Rapid Growth of Organic Aerosol Nanoparticles over a Wide Tropospheric Temperature Range. Proc. Natl. Acad. Sci. U. S. A. 2018, 115 (37), 9122-9127.

(9) Tröstl, J.; Chuang, W. K.; Gordon, H.; Heinritzi, M.; Yan, C.; Molteni, U.; Ahlm, L.; Frege, C.; Bianchi, F.; Wagner, R.; et al. The Role of Low-Volatility Organic Compounds in Initial Particle Growth in the Atmosphere. Nature 2016, 533 (7604), 527-531.

(10) Bianchi, F.; Trostl, J.; Junninen, H.; Frege, C.; Henne, S.; Hoyle, C. R. R.; Molteni, U.; Herrmann, E.; Adamov, A.; Bukowiecki, N.; et al. New Particle Formation in the Free Troposphere: A Question of Chemistry and Timing. Science (Washington, DC, U. S.) 2016, 352 (6289), 1109-1112.

(11) Jokinen, T.; Kontkanen, J.; Lehtipalo, K.; Manninen, H. E.; Aalto, J.; Porcar-Castell, A.; Garmash, O.; Nieminen, T.; Ehn, M.; Kangasluoma, J.; et al. Solar Eclipse Demonstrating the Importance of Photochemistry in New Particle Formation. Sci. Rep. 2017, 7 (1), 45707.

(12) Mutzel, A.; Poulain, L.; Berndt, T.; Iinuma, Y.; Rodigast, M.; Böge, O.; Richters, S.; Spindler, G.; Sipilä, M.; Jokinen, T.; et al. Highly Oxidized Multifunctional Organic Compounds Observed in Tropospheric Particles: A Field and Laboratory Study. Environ. Sci. Technol. 2015, 49 (13), 7754-7761.

(13) Carslaw, K. S.; Lee, L. a; Reddington, C. L.; Pringle, K. J.; Rap, A.; Forster, P. M.; Mann, G. W.; Spracklen, D. V.; Woodhouse, M. T.; Regayre, L. a; et al. Large Contribution of Natural Aerosols to Uncertainty in Indirect Forcing. Nature 2013, 503 (7474), 67-71.

(14) Gordon, H.; Sengupta, K.; Rap, A.; Duplissy, J.; Frege, C.; Williamson, C.; Heinritzi, M.; Simon, M.; Yan, C.; Almeida, J.; et al. Reduced Anthropogenic Aerosol Radiative Forcing Caused by Biogenic New Particle Formation. Proc. Natl. Acad. Sci. U. S. A. 2016, 113 (43), 12053-12058.

(15) Jokinen, T.; Berndt, T.; Makkonen, R.; Kerminen, V.; Junninen, H.; Paasonen, P.; Stratmann, F.; Herrmann, H.; Guenther, A. B.; Worsnop, D. R.; et al. Production of Extremely Low Volatile Organic Compounds from Biogenic Emissions: Measured Yields and Atmospheric Implications. Proc. Natl. Acad. Sci. U. S. A. 2015, 112 (23), $7123-7128$

(16) Berndt, T.; Richters, S.; Jokinen, T.; Hyttinen, N.; Kurtén, T.; Otkjær, R. V.; Kjaergaard, H. G.; Stratmann, F.; Herrmann, H.; Sipilä, M.; et al. Hydroxyl Radical-Induced Formation of Highly Oxidized Organic Compounds. Nat. Commun. 2016, 7 (1), 13677.

(17) Richters, S.; Herrmann, H.; Berndt, T. Highly Oxidized $\mathrm{RO}_{2}$ Radicals and Consecutive Products from the Ozonolysis of Three Sesquiterpenes. Environ. Sci. Technol. 2016, 50 (5), 2354-2362.

(18) Jokinen, T.; Kausiala, O.; Garmash, O.; Peräkylä, O.; Junninen, H.; Schobesberger, S.; Yan, C.; Sipilä, M.; Rissanen, M. P. Production of Highly Oxidized Organic Compounds from Ozonolysis of $\beta$ Caryophyllene: Laboratory and Field Measurements. Boreal Environ. Res. 2016, 21 (3-4), 262-273.

(19) Rissanen, M. P.; Kurtén, T.; Sipilä, M.; Thornton, J. a.; Kausiala, O.; Garmash, O.; Kjaergaard, H. G.; Petäjä, T.; Worsnop, D. R.; Ehn, M.; et al. Effects of Chemical Complexity on the Autoxidation Mechanisms of Endocyclic Alkene Ozonolysis Products: From Methylcyclohexenes toward Understanding $\alpha$-Pinene. J. Phys. Chem. A 2015, 119 (19), 4633-4650. 
(20) Rissanen, M. P.; Kurtén, T.; Sipilä, M.; Thornton, J. A.; Kangasluoma, J.; Sarnela, N.; Junninen, H.; Jørgensen, S.; Schallhart, S.; Kajos, M. K.; et al. The Formation of Highly Oxidized Multifunctional Products in the Ozonolysis of Cyclohexene. J. Am. Chem. Soc. 2014, 136 (44), 15596-15606.

(21) Berndt, T.; Richters, S.; Kaethner, R.; Voigtländer, J.; Stratmann, F.; Sipilä, M.; Kulmala, M.; Herrmann, H. Gas-Phase Ozonolysis of Cycloalkenes: Formation of Highly Oxidized $\mathrm{RO}_{2}$ Radicals and Their Reactions with $\mathrm{NO}, \mathrm{NO}_{2}, \mathrm{SO}_{2}$, and Other $\mathrm{RO}_{2}$ Radicals. J. Phys. Chem. A 2015, 119 (41), 10336-10348.

(22) Mentel, T. F.; Springer, M.; Ehn, M.; Kleist, E.; Pullinen, I.; Kurtén, T.; Rissanen, M.; Wahner, A.; Wildt, J. Formation of Highly Oxidized Multifunctional Compounds: Autoxidation of Peroxy Radicals Formed in the Ozonolysis of Alkenes - Deduced from Structure-product Relationships. Atmos. Chem. Phys. 2015, 15 (12), 6745-6765.

(23) Molteni, U.; Bianchi, F.; Klein, F.; El Haddad, I.; Frege, C.; Rossi, M. J.; Dommen, J.; Baltensperger, U. Formation of Highly Oxygenated Organic Molecules from Aromatic Compounds. Atmos. Chem. Phys. 2018, 18 (3), 1909-1921.

(24) Wang, S.; Wu, R.; Berndt, T.; Ehn, M.; Wang, L. Formation of Highly Oxidized Radicals and Multifunctional Products from the Atmospheric Oxidation of Alkylbenzenes. Environ. Sci. Technol. 2017, 51 (15), 8442-8449.

(25) Berndt, T.; Scholz, W.; Mentler, B.; Fischer, L.; Herrmann, H.; Kulmala, M.; Hansel, A. Accretion Product Formation from Self- and Cross-Reactions of $\mathrm{RO}_{2}$ Radicals in the Atmosphere. Angew. Chem., Int. Ed. 2018, 57 (14), 3820-3824.

(26) Rissanen, M. P. $\mathrm{NO}_{2}$ Suppression of Autoxidation-Inhibition of Gas-Phase Highly Oxidized Dimer Product Formation. ACS Earth Space Chem. 2018, 2 (11), 1211-1219.

(27) Richters, S.; Pfeifle, M.; Olzmann, M.; Berndt, T. EndoCyclization of Unsaturated $\mathrm{RO}_{2}$ Radicals from the Gas-Phase Ozonolysis of Cyclohexadienes. Chem. Commun. 2017, 53 (29), 4132-4135.

(28) Jenkin, M. E.; Saunders, S. M.; Pilling, M. J. The Tropospheric Degradation of Volatile Organic Compounds: A Protocol for Mechanism Development. Atmos. Environ. 1997, 31 (1), 81-104.

(29) Saunders, S. M.; Jenkin, M. E.; Derwent, R. G.; Pilling, M. J. Protocol for the Development of the Master Chemical Mechanism, MCM v3 (Part A): Tropospheric Degradation of Non-Aromatic Volatile Organic Compounds. Atmos. Chem. Phys. 2003, 3 (1), 161180.

(30) Schnitzhofer, R.; Metzger, A.; Breitenlechner, M.; Jud, W.; Heinritzi, M.; De Menezes, L. P.; Duplissy, J.; Guida, R.; Haider, S.; Kirkby, J.; et al. Characterisation of Organic Contaminants in the CLOUD Chamber at CERN. Atmos. Meas. Tech. 2014, 7 (7), 21592168.

(31) Graus, M.; Müller, M.; Hansel, A. High Resolution PTR-TOF: Quantification and Formula Confirmation of VOC in Real Time. J. Am. Soc. Mass Spectrom. 2010, 21 (6), 1037-1044.

(32) Kürten, A.; Jokinen, T.; Simon, M.; Sipilä, M.; Sarnela, N.; Junninen, H.; Adamov, A.; Almeida, J.; Amorim, A.; Bianchi, F.; et al. Neutral Molecular Cluster Formation of Sulfuric Acid-dimethylamine Observed in Real Time under Atmospheric Conditions. Proc. Natl. Acad. Sci. U. S. A. 2014, 111 (42), 15019-15024.

(33) Junninen, H.; Ehn, M.; Petäjä, T.; Luosujärvi, L.; Kotiaho, T.; Kostiainen, R.; Rohner, U.; Gonin, M.; Fuhrer, K.; Kulmala, M.; et al. A High-Resolution Mass Spectrometer to Measure Atmospheric Ion Composition. Atmos. Meas. Tech. 2010, 3 (4), 1039-1053.

(34) Heinritzi, M.; Simon, M.; Steiner, G.; Wagner, A. C.; Kürten, A.; Hansel, A.; Curtius, J. Characterization of the Mass-Dependent Transmission Efficiency of a CIMS. Atmos. Meas. Tech. 2016, 9 (4), $1449-1460$.

(35) Bianchi, F.; Kurtén, T.; Riva, M.; Mohr, C.; Rissanen, M. P.; Roldin, P.; Berndt, T.; Crounse, J. D.; Wennberg, P. O.; Mentel, T. F.; et al. Highly Oxygenated Organic Molecules (HOM) from Gas-Phase Autoxidation Involving Peroxy Radicals: A Key Contributor to Atmospheric Aerosol. Chem. Rev. 2019, 119 (6), 3472-3509.
(36) Kurtén, T.; Rissanen, M. P.; Mackeprang, K.; Thornton, J. A.; Hyttinen, N.; Jørgensen, S.; Ehn, M.; Kjaergaard, H. G. Computational Study of Hydrogen Shifts and Ring-Opening Mechanisms in $\alpha$-Pinene Ozonolysis Products. J. Phys. Chem. A 2015, 119 (46), 11366-11375.

(37) Osborn, D. L. Reaction Mechanisms on Multiwell Potential Energy Surfaces in Combustion (and Atmospheric) Chemistry. Annu. Rev. Phys. Chem. 2017, 68 (1), 233-260.

(38) Lee, R.; Gryn'ova, G.; Ingold, K. U.; Coote, M. L. Why Are SecAlkylperoxyl Bimolecular Self-Reactions Orders of Magnitude Faster than the Analogous Reactions of Tert-Alkylperoxyls? The Unanticipated Role of CH Hydrogen Bond Donation. Phys. Chem. Chem. Phys. 2016, 18 (34), 23673-23679.

(39) MathWorks. MATLAB; MathWorks: Natick, MA, 2016.

(40) Praske, E.; Otkjær, R. V.; Crounse, J. D.; Hethcox, J. C.; Stoltz, B. M.; Kjaergaard, H. G.; Wennberg, P. O. Atmospheric Autoxidation Is Increasingly Important in Urban and Suburban North America. Proc. Natl. Acad. Sci. U. S. A. 2018, 115 (1), 64-69.

(41) Otkjær, R. V.; Jakobsen, H. H.; Tram, C. M.; Kjaergaard, H. G. Calculated Hydrogen Shift Rate Constants in Substituted Alkyl Peroxy Radicals. J. Phys. Chem. A 2018, 122 (43), 8665-8673.

(42) Zhao, Y.; Thornton, J. A.; Pye, H. O. T. Quantitative Constraints on Autoxidation and Dimer Formation from Direct Probing of Monoterpene-Derived Peroxy Radical. Proc. Natl. Acad. Sci. U. S. A. 2018, 115 (48), 12142-12147.

(43) Orlando, J. J.; Tyndall, G. S. Laboratory Studies of Organic Peroxy Radical Chemistry: An Overview with Emphasis on Recent Issues of Atmospheric Significance. Chem. Soc. Rev. 2012, 41 (19), 6294.

(44) Vereecken, L.; Peeters, J. Decomposition of Substituted Alkoxy Radicals-Part I: A Generalized Structure-Activity Relationship for Reaction Barrier Heights. Phys. Chem. Chem. Phys. 2009, 11 (40), 9062-9074.

(45) Berndt, T.; Mentler, B.; Scholz, W.; Fischer, L.; Herrmann, H.; Kulmala, M.; Hansel, A. Accretion Product Formation from Ozonolysis and $\mathrm{OH}$ Radical Reaction of $\alpha$-Pinene: Mechanistic Insight and the Influence of Isoprene and Ethylene. Environ. Sci. Technol. 2018, 52 (19), 11069-11077.

(46) Hornbrook, R. S.; Crawford, J. H.; Edwards, G. D.; Goyea, O.; Mauldin, R. L., III; Olson, J. S.; Cantrell, C. A. Measurements of Tropospheric $\mathrm{HO}_{2}$ and $\mathrm{RO}_{2}$ by Oxygen Dilution Modulation and Chemical Ionization Mass Spectrometry. Atmos. Meas. Tech. 2011, 4 (4), 735-756. 